Brinkmann et. al

\title{
1 Aryl hydrocarbon receptor-dependent and -independent pathways 2 mediate curcumin anti-aging effects
}

3

4

Vanessa Brinkmann ${ }^{1,2, \wedge}$, , Margherita Romeo ${ }^{1,2, \#}$, Lucie Larigot $^{3}$, Anne Hemmers ${ }^{2}$, Lisa Tschage $^{2}$, Jennifer Kleinjohann ${ }^{2}$, Alfonso Schiavi ${ }^{1,2}$, Swantje Steinwachs ${ }^{2}$, Charlotte Esser ${ }^{2}$, Ralph Menzel ${ }^{4}$, Sara Giani Tagliabue ${ }^{5}$, Laura Bonati ${ }^{5}$, Fiona Cox ${ }^{1,6}$, Niloofar Ale-Agha ${ }^{1}$, Philipp Jakobs $^{1}$, Joachim Altschmied ${ }^{1,2}$, Judith Haendeler ${ }^{1}$, Xavier Coumoul $^{3}$, Natascia Ventura ${ }^{1,2, ~ *}$

1. Institute of Clinical Chemistry and Laboratory Diagnostic, Medical Faculty, Heinrich Heine University, Düsseldorf, Moorenstr 5, 40225 Düsseldorf, Germany

2. Leibniz Institute for Environmental Medicine (IUF), Auf'm Hennekamp 50, 40225 Düsseldorf, Germany

3. Faculté des Sciences Fondamentales et Biomédicales, Université de Paris, 45 rue des SaintsPères, F-75006, Paris, France

4. Institute of Biology, Humboldt-University Berlin, Philippstr. 13, 10115 Berlin, Germany

5. Department of Earth and Environmental Sciences, University of Milano-Bicocca, Piazza della Scienza 1, 20126 Milano, Italy

6. Institute of Clinical Pharmacology and Pharmacology, Medical Faculty, University Hospital and Heinrich Heine University, Düsseldorf, Moorenstr 5, 40225 Düsseldorf, Germany

Lead contact: Natascia Ventura natascia.ventura@uni-duesseldorf.de,

^ Current address: Institute of Toxicology, Medical Faculty, Heinrich Heine University, Düsseldorf, Moorenstr 5, 40225 Düsseldorf, Germany

\# Equally contributed to the paper

* Correspondence: natascia.ventura@uni-duesseldorf.de, 0049-211-3389203

\section{Graphical Abstract}

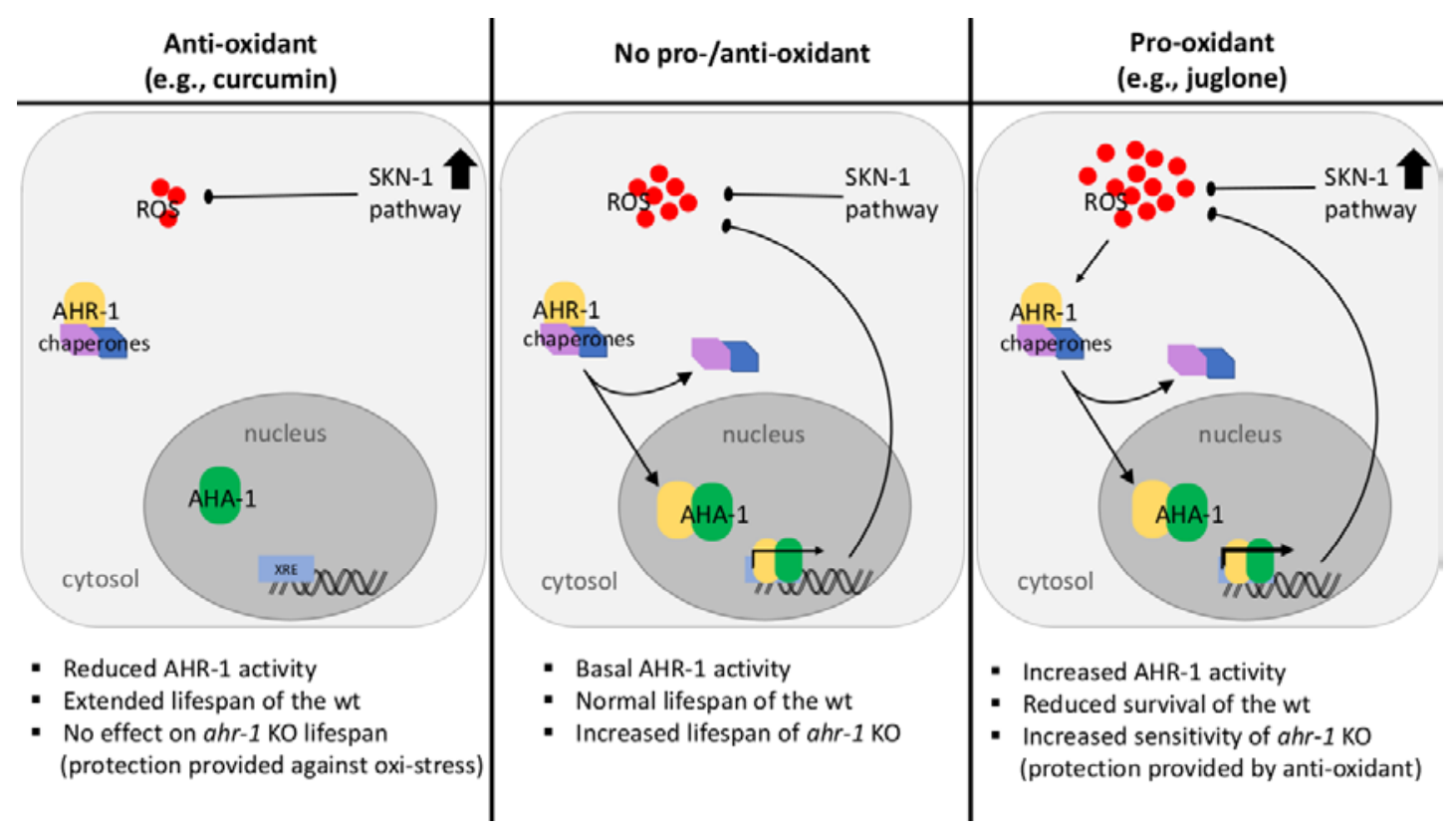


Brinkmann et. al

\section{Abstract}

The aryl hydrocarbon receptor (AhR) is a ligand-activated transcription factor whose activity can be modulated by polyphenols such as curcumin. AhR and curcumin have evolutionarily conserved effects on aging. Here, we investigated whether and how the AhR mediates the anti-aging effects of curcumin across species. Using a combination of in vivo, in vitro, and in silico analyses, we demonstrated that curcumin has AhR-dependent or -independent effects in a context-specific manner. We found that in Caenorhabditis elegans, AhR mediates curcumin-induced lifespan extension, most likely through a ligand-independent inhibitory mechanism related to its antioxidant activity. Curcumin also showed AhR-independent antiaging activities such as protection against aggregation-prone proteins and oxidative stress in C. elegans and promotion of the migratory capacity of human primary endothelial cells. These AhR-independent effects are largely mediated by the Nrf2/SKN-1 pathway.

Keywords: Aryl hydrocarbon Receptor, curcumin, oxidative stress, Caenorhabditis elegans, mice, endothelial cells, in vivo, in vitro, in silico 
Brinkmann et. al

44

45

46

47

48

49

50

51

52

\section{Introduction}

The aryl hydrocarbon receptor (AhR) is a ubiquitous ligand-activated transcription factor identified as a determinant for the toxicological response to 2,3,7,8-tetrachlorodibenzo-p-dioxin (TCDD) in mammals (Poland et al., 1976). AhR signaling pathways have been well described in mammalian cells. Briefly, unliganded AhR is localized in the cytoplasm and stabilized by diverse co-factors, such as 90-kDa heat shock protein (Hsp90), the AHR-interacting protein (AIP), and the chaperone p23. Binding to exogenous (e.g. TCDD) or endogenous (e.g. kynurenine) ligands, promotes the translocation of this complex into the nucleus where AhR dissociates from its co-factors and assembles in a heterodimer with the AHR nuclear translocator (ARNT). The resulting AHR/ARNT complex binds to the xenobiotic responsive elements (XREs) of a battery of responsive phase I and II detoxification genes, eventually leading to the ligands' degradation (Abel and Haarmann-Stemmann, 2010). Apart from its role in xenobiotic response, functions for the $A h R$ in a variety of pathophysiological processes ranging from immunity (Gutierrez-Vazquez and Quintana, 2018, Zhang et al., 2010), inflammation (Vondracek et al., 2011, Hanieh, 2014), lipid and glucose metabolism (Minami et al., 2008, Diani-Moore et al., 2010) to cardiovascular, liver and other organs' diseases (Yi et al., 2018, Schmidt et al., 1996, Fernandez-Salguero et al., 1995, Fernandez-Salguero et al., 1997) have been discovered in the last decades. Growing evidence also points to disparate and seemly contradictory roles of AhR in the aging process, which could nonetheless be reconciled taking into account tissue-, dose- and species-specific effects (Brinkmann et al., 2020a). A negative role for AhR in aging and age-associated features has been described across species (Eckers et al., 2016, Williams et al., 2014). Compared to the wild-type Caenorhabditis elegans the AhR mutant strain, ahr-1(ju145), has an extended life- and healthspan; in mice, AhR deficiency improves vessel function and increases activity of the nitric oxide synthase and therefore, the NO bioavailability; and, finally, a positive correlation was found between AhR expression and vessel stiffness middle-aged and aged human subjects (Eckers et al., 2016). Furthermore, in an epidemiological study on a Chinese population AhR expression was related to the incidence of coronary arterial disease (Huang et al., 2015). 
Brinkmann et. al

Of note, many compounds impacting aging or age-related diseases (Sakakibara et al., 2005, Okey et al., 1984, Gao et al., 2015) can modulate AhR activity (Denison et al., 2002, Ashida et al., 2000, Zhang et al., 2003). While activation of AhR by xenobiotics leads to different cancers in mammals (Mandal, 2005, Marinkovic et al., 2010), dietary and environmental factors were shown to have opposite AhR-dependent effects on C. elegans' health-span (Brinkmann et al., 2020b). Among the dietary AhR modulators, polyphenols such as curcumin have been largely studied for their pro-health effects. Curcumin, is a yellow pigment from Curcuma longa, with numerous evolutionarily conserved beneficial properties, including antioxidant, anti-inflammatory and anti-aging activities (Aggarwal and Harikumar, 2009). Curcumin prevents protein aggregation and increases longevity in C. elegans and Drosophila via modulation of protein homeostasis (Alavez et al., 2011, Liu et al., 2014, Caesar et al., 2012). Moreover, when administered to an Alzheimer's Disease transgenic mouse model, it significantly reduced the total amyloid-beta (A $\beta$ ) burden (Lim et al., 2001). In old mice, curcumin restored NO-bioavailability thus reducing oxidative stress and improving endothelial dysfunction and artery stiffness assessed by aortic pulse wave velocity (PWV) - one of the most important clinical measurements or markers of large elastic artery stiffness (Fleenor et al., 2013). Several studies in humans also showed a protective effect of curcumin on cardiovascular health (Oliver et al., 2016). However, the mode of action of curcumin is still largely unclear, and, more importantly, whether its beneficial health effects are mediated by AhR has not been investigated (Xue et al., 2017, Jeuken et al., 2003).

Model organisms such as the nematode $C$. elegans have been instrumental to identify genetic and environmental determinants of aging. This is due to its many advantageous properties, including its easy laboratory handling, short lifespan, and the production of a large number of progeny by self-fertilization. C. elegans' genome is completely sequenced and most of its genes and pathways are evolutionarily conserved. The protein sequence of $A h R$ is conserved during the evolution and in C. elegans the orthologs of AhR and ARNT are encoded by the AhR-related (ahr-1) and ahr-1 associated (aha-1) genes, respectively (Powell-Coffman et al., 1998). The corresponding proteins, AHR-1 and AHA-1, share about $40 \%$ of sequence identity 
Brinkmann et. al

100

101

102

103

104

105

106

107

108

109

110

111

112

113

with the mammalian ones and form a heterodimer (also with the mammalian counterparts) which can bind XREs of the target genes in vitro (Bell and Poland, 2000). AHR-1 is mostly expressed in neuronal cell types such as GABAergic neurons (Huang et al., 2004) and it plays a key role in controlling neuronal development (Qin and Powell-Coffman, 2004). Unlike vertebrates AhR, AHR-1 does not bind TCDD and other related xenobiotics (Powell-Coffman et al., 1998, Butler et al., 2001), yet it shares with mammalian AhR common features in the regulation of neuronal processes, development and fertility (Qin and Powell-Coffman, 2004, Qin et al., 2006, Huang et al., 2004, Smith et al., 2013, Baba et al., 2008, Aarnio et al., 2010) ultimately suggesting that the ancestral AhR was not directly involved in controlling genes for degradation of toxic ligands (Hahn et al., 1997, Hahn, 2002). We thus reckoned C. elegans a unique and powerful model system to identify and study ancestral functions of the AhR possibly unrelated to its xenobiotics response.

In this study, we investigated the role of AhR in curcumin anti-aging effects across species. Through a combination of in vivo, in vitro, and in silico analyses we found that curcumin displays different beneficial anti-aging effects through uncoupled ahr-1-dependent and -independent mechanisms. We found that C. elegans ahr-1-depleted animals are longlived but more sensitive to oxidative stress. While curcumin did not further extend the lifespan of the C. elegans ahr-1 mutants it promoted their resistance to oxidative stress. Curcumin also promoted antioxidant response and migratory capacity of human primary endothelial cells (EC) independently of $\mathrm{AhR}$, an effect that primarily relied on Nrf2/SKN-1 across species. Coupling results from a cellular reporter assay and in-silico modeling of the AHR-1 ligand-binding domain (LBD), we then showed that curcumin most likely suppressed AHR-1 activity in a ligand-binding-independent manner. Notably, and in line with the data in C. elegans and EC, curcumin and pro-oxidants displayed opposite effects on AHR-1 activity, implying curcumin may modulate AHR-1 activity through its anti-oxidant capacity either directly or indirectly via regulation of Nrf2/SKN-1 or other redox regulatory proteins. 
Brinkmann et. al

\section{Results}

\section{Curcumin promotes healthspan in an AhR-dependent and -independent manner}

128 Loss of ahr-1 promotes C. elegans' health- and lifespan in basal conditions (Eckers et al., 129 2016) and it negatively impacts age-related traits in response to mammalian AhR modulators 130 like benzo[a]pyrene (BaP), UVB light, and microbiota (Brinkmann et al., 2020b). Dietary 131 polyphenols, such as curcumin, form an important group of mammalians' AhR modulators with 132 pro-longevity effects in C. elegans (Liao et al., 2011, Nishiumi et al., 2007) and we thus 133 investigated the lifespan-extending effect of curcumin for its ahr-1 dependency. Curcumin 134 reproducibly and significantly extended the life- and health-span of C. elegans in an ahr-1135 dependent manner (Fig 1A, B). Previously, we have shown that loss of ahr-1 also extends the 136 lifespan in Huntington's disease and Parkinson's disease models, with muscle-overexpression 137 of aggregation-prone polyglutamine (polyQ40) and $\alpha$-synuclein ( $\alpha$-syn) respectively, while at 138 the same time increasing their content of protein aggregates (Brinkmann et al., 2020b). 139 Interestingly, curcumin treatment increased the number of polyQ40 and a-syn aggregates to

140 the same extent as ahr-1 loss of function (Fig 1C). Curcumin also promoted lifespan and 141 locomotory ability in these disease models (Fig 1D, E) but the effects of ahr-1 loss and 142 curcumin supplementation were additive in the PolyQ background (Fig 1D), revealing AHR-1-

143 independent protective functions of curcumin at least in this compromised background. 
Brinkmann et. al

A

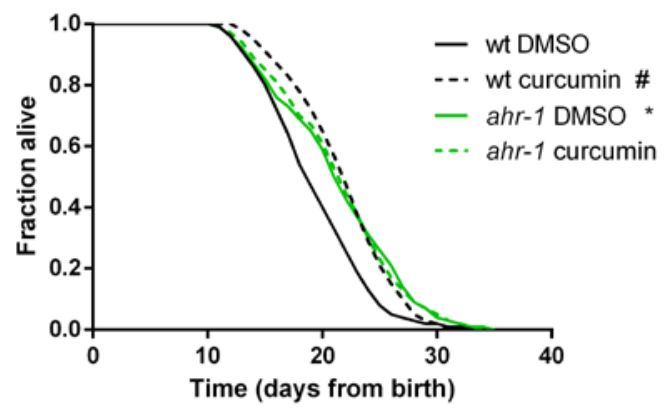

C PolyQ40

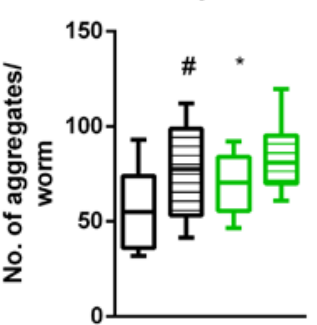

D

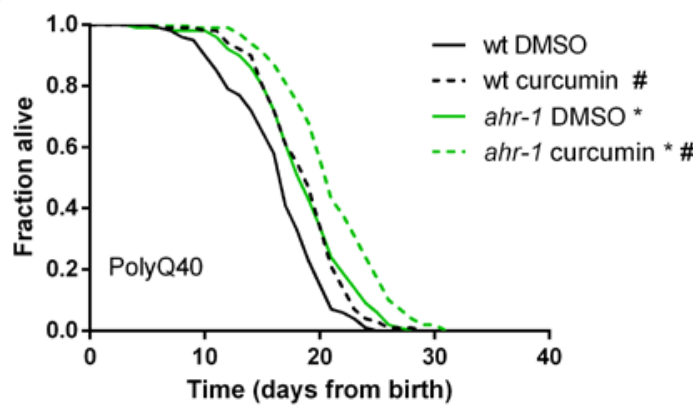

B

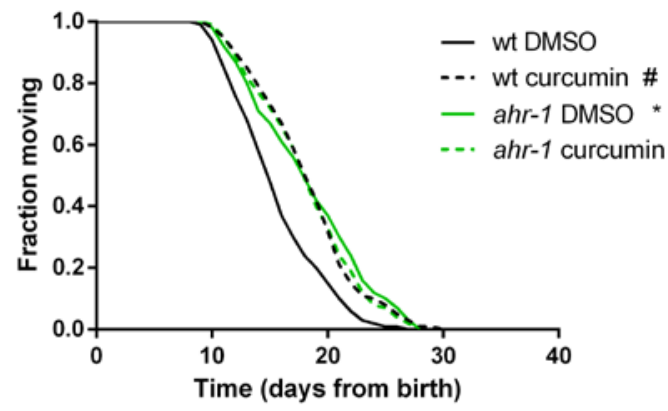

$\square$ wt DMSO

$\boxminus$ wt curcumin

$\square$ ahr-1 DMSO

ahr-1 curcumin

E

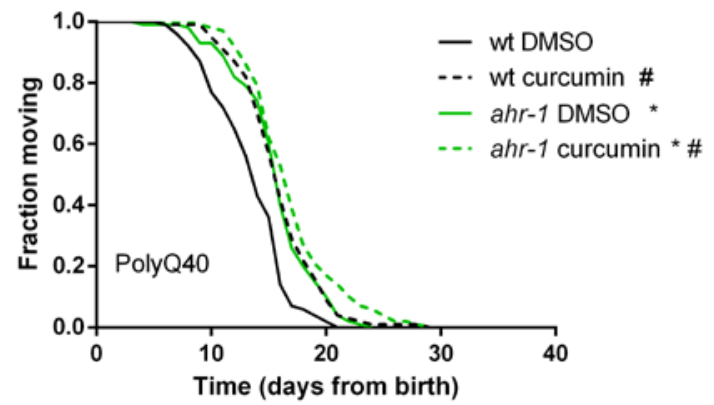

Figure 1. Curcumin promotes health in an AHR-1-dependent and -independent manner.

Lifespan (A) and health-span (B) curves of DMSO- or curcumin-treated wt and ahr-1 nematodes. Survival curves show pooled data of 290-300 worms/condition in 5 experiments. Statistical test: LogRank test, \#significance vs. DMSO, *significance vs. wt, Bonferroni p-value $<0.05$. C) Quantification of aggregates in 10-days old polyQ;wt and polyQ;ahr-1 (left panel) or 7-days old asyn;wt and asyn;ahr-1 (right panel). Boxplots show pooled data from 59-111 worms/condition in 3 experiments. Statistical test: 1 -way ANOVA with Tukey's multiple comparisons test, *p-value $<0.05$ vs. wt, \#p-value $<0.05$ vs. DMSO. D-E) Life-/healthspan of polyQ;wt and polyQ;ahr-1. Survival curves show pooled data of 180 worms/condition in 3 experiments. Statistical test: Log-Rank test, \#significance vs. DMSO, *significance vs. wt, Bonferroni p-value $<0.05$.

157 In search of possible downstream ahr-1-dependent effectors of curcumin, we took targeted

158 and unbiased approaches. We examined the expression of classical mammalian AhR target 
Brinkmann et. al

160 in mammalian cells (Rinaldi et al., 2002, Choi et al., 2008). However, the quantification of 47

161 different cyps in C. elegans by semi-quantitative Real-time PCR (qPCR) revealed that only 162 cyp-13B1 was significantly up-regulated either by ahr-1 depletion or by curcumin in an ahr-1dependent manner (Fig S1A-B), while three other cyps (i.e. cyp-13A5 and cyp-13A8, cyp42A1) were increased by curcumin only in the absence of ahr-1 (Fig S1). These data, along with other works (Brinkmann et al., 2020b, Jones et al., 2013), suggest that cyps are likely not the major targets of CeAhR. This is also supported by our transcriptomic analysis in wild-type and ahr-1 mutants. Indeed, consistent with the role of AHR-1 in neuronal determination (Huang et al., 2004, Qin and Powell-Coffman, 2004, Smith et al., 2013, Qin et al., 2006), the gene expression changes between wild-type and ahr-1 mutants showed enrichment in processes linked to neuronal development and differentiation and no major changes in classical

171 detoxification genes (Fig 2A). qPCR analysis of some of the most up- and down-regulated 172 genes between ahr-1(ju145) and wild-type (atf-2, K04H4.2, egl-46, T20F5.4, ptr-4, dyf-7, clec173 209, C01B4.6, C01B4.7, F56A4.3) mostly confirmed their ahr-1-dependency in basal 174 conditions (Fig 2B) but neither UVB (Brinkmann et al., 2020b) nor curcumin (Fig 2C) 175 significantly affected the expression of these genes. We wondered whether the expression 176 changes in these genes are evolutionarily conserved and assessed their expression in different 177 tissues (i.e. brain, liver, gut, and blood) of 8- and 18-months-old wild-type and AhR KO mice. 178 Some genes showed a tendency for an increased expression in young (atf-2 homolog) or old 179 (Ipr-4/5 homologs) mice in a tissue-specific manner, but neither obvious pattern nor conserved 180 changes were observed (Fig S2). These results reflect possible species-specific differences 181 or tissue-dependent AhR transcriptional activity in mammals overlooked by whole-animal transcriptomic analysis in C. elegans. 
bioRxiv preprint doi: https://doi.org/10.1101/2022.02.10.479676; this version posted February 10, 2022. The copyright holder for this preprint (which was not certified by peer review) is the author/funder. All rights reserved. No reuse allowed without permission.

Brinkmann et. al

A

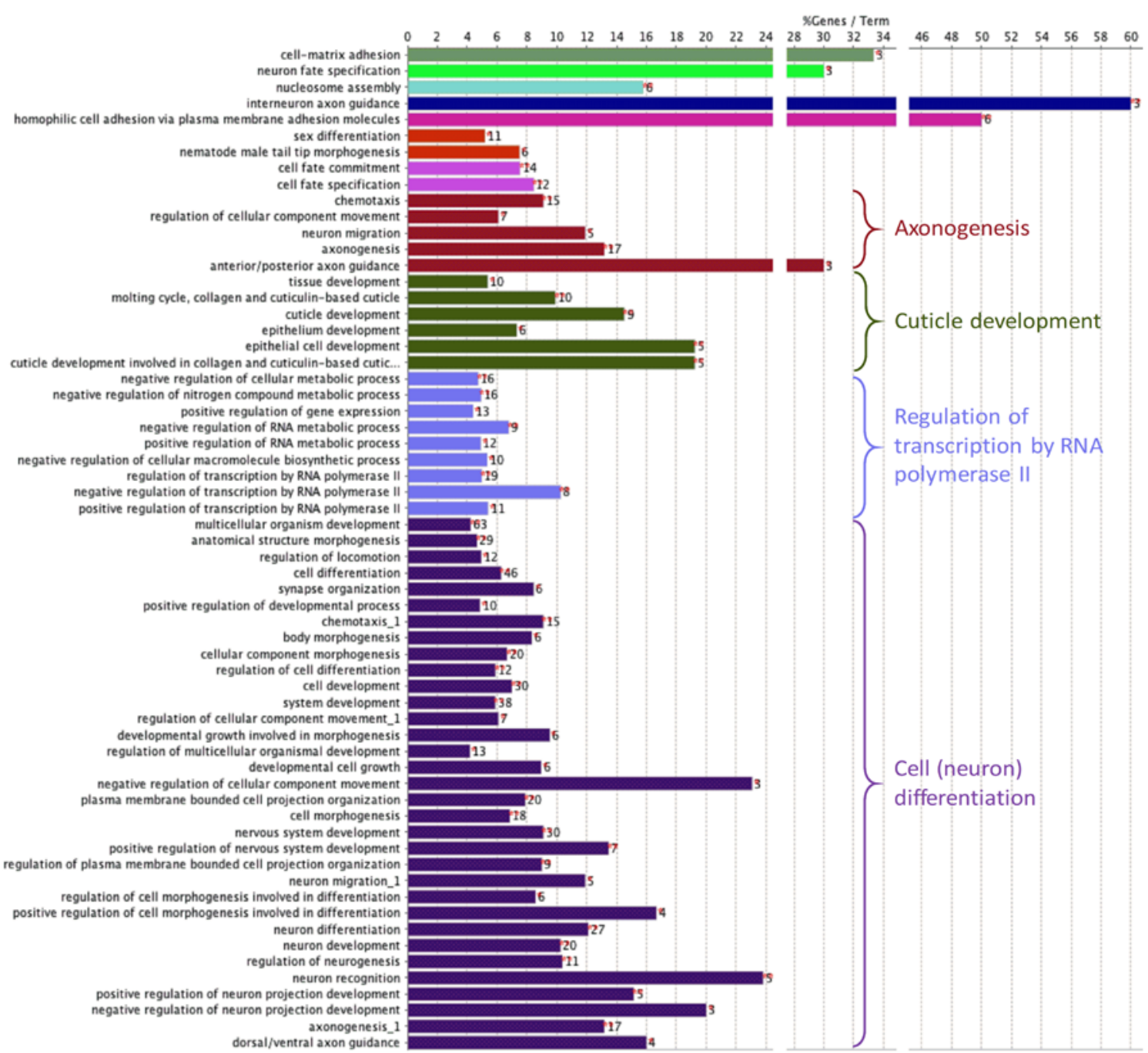

B

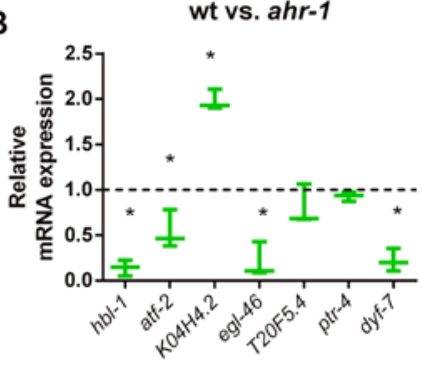

C

wt DMSO vs. wt curcumin

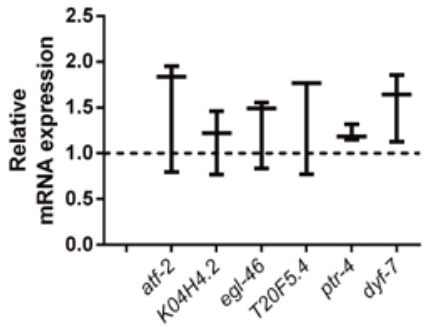

wt vs. ahr-1

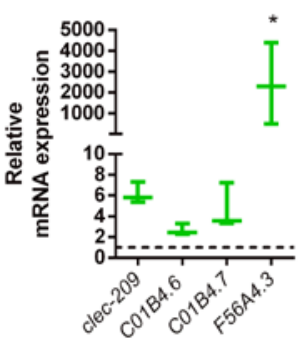

wt DMSO vs. wt curcumin

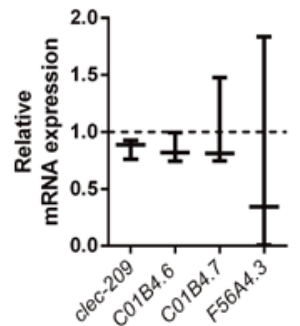

D

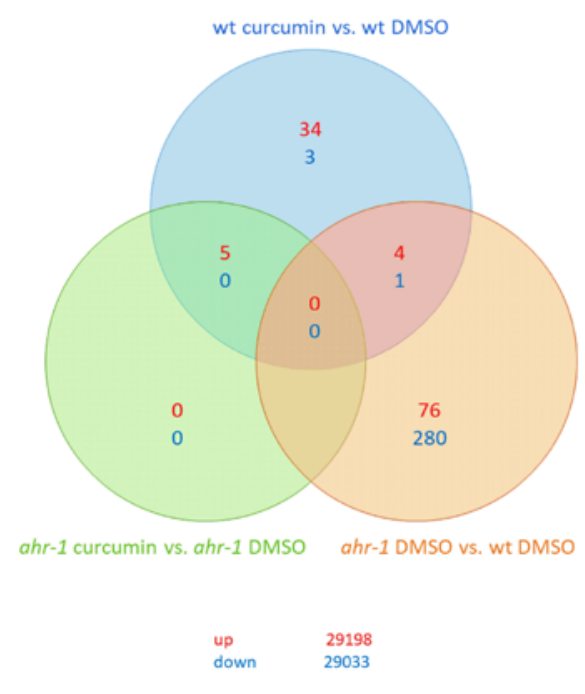

Figure 2. Genes differentially regulated by curcumin are primarily regulated in an ahr-1-

A) Gene Ontology (GO) enrichment for biological processes after GO term fusion in ahr-1 vs. wt. B-C) The expression of the strongest down- and up-regulated genes between wt and ahr-1 (Brinkmann et al., 2020b) was assessed by qPCR in wt vs. ahr-1 (B) and DMSO- vs. curcumin-treated nematodes 
Brinkmann et. al

(C). Boxplots show data of 3 experiments. The expression is shown relative to DMSO-treated wt (dashed line). Statistical test: 1-way ANOVA with Tukey's multiple comparisons test, ${ }^{*}$ p-value $<0.05$ vs. wt, " $p$-value < 0.05 vs. DMSO. D) Venn diagram of differentially expressed genes on the microarray. The number of genes that were differentially up- or down-regulated between the indicated conditions is shown in red and blue, respectively. The numbers in the interchanges refer to the genes that occurred in both comparisons. The values in the lower right corner show the number of genes on the array that were not differentially expressed.

A thorough examination of the most differentially expressed genes between $C$. elegans wildtype and ahr-1(ju145) revealed that the expression of many of these genes is affected in C. elegans during aging and by dietary mammalian AhR modulators (e.g. quercetin, resveratrol) (Brinkmann et al., 2020b), thus suggesting a role for AHR-1 in polyphenolmodulated gene expression. In line with this scenario, the microarray data showed that most of the genes differentially expressed upon curcumin treatment were indeed regulated in an ahr-1-dependent manner (Fig 2D; Table 1). Out of 47 genes altered by curcumin in the wildtype (43 up- and 4 down-regulated), only 5 were also induced by curcumin in ahr-1(ju145). Among the genes regulated by curcumin in an AHR-1-dependent manner were phase II enzymes and interestingly, some of them (ugt-9 and ugt-29), were regulated in the same direction by curcumin or by loss of ahr-1 (Table 1). Thus, we checked their expression and that of additional ugts (ugt-45 and ugt-57) that were differentially expressed when applying a less restrictive statistical analysis not corrected for multiple comparisons. Of the examined genes ugt-45 was increased in ahr-1(ju145) and by curcumin treatment (Fig 3A, B). We also observed changes in the expression of some detoxification genes between wild-type and AhR $\mathrm{KO}$ mice, in a tissue-dependent manner. The differential expression of those genes was highest in the brain, where Ugt2a3 (ugt-9 and ugt-29 in C. elegans) was down- and Hpgds (gst-4 in C. elegans) was up-regulated (Fig S3A). There was no change in the expression of any of the tested genes in the liver samples of mice (Fig S3B). In line with the C. elegans data, the ugt-45 murine homolog Ugt3a2 showed a tendency towards overexpression in the intestines of Ahr KO mice (Fig S3C). Notably, ugt-45 RNAi prevented the beneficial effects on life- and health-span promoted by curcumin (Fig 3C, D) or ahr-1 depletion (Fig 3E, F) indicating 
Brinkmann et. al

219 the two interventions may rely on jointly modulated downstream signaling to elicit their anti-

220 aging activity.

221 Table 1. List of genes from the microarray analysis.

\begin{tabular}{|c|c|c|c|c|c|}
\hline $\begin{array}{c}\text { Gene/ Sequence } \\
\text { name }\end{array}$ & Gene class ${ }^{a}$ & Molecular function ${ }^{a}$ & $\log F C^{b}$ & $\begin{array}{l}\text { adj. P- } \\
\text { value }\end{array}$ & $\begin{array}{c}\text { Selected } \\
\text { modulators }^{a}\end{array}$ \\
\hline H43E16.1 & unknown & unknown & 1.53 & 0.021 & $\begin{array}{l}\text { bacterial } \\
\text { infection, } \\
\text { quercetin, } \\
\text { rotenone, } \\
\text { aging, } \\
\text { nuo-6(qm200) }\end{array}$ \\
\hline numr-1 & $\begin{array}{l}\text { Nuclear } \\
\text { localized } \\
\text { metal } \\
\text { responsive }\end{array}$ & unknown & 1.42 & 0.034 & $\begin{array}{c}\text { bacterial } \\
\text { infection, } \\
\text { quercetin, } \\
\text { spg-7 RNAi, } \\
\text { isp-1(qm150), } \\
\text { nuo-6(qm200), } \\
\text { aging }\end{array}$ \\
\hline mul-1 & Mucin-like & unknown & 1.34 & 0.029 & $\begin{array}{c}\text { resveratrol, } \\
\text { bacterial } \\
\text { infection, } \\
\text { spg-7 RNAi, } \\
\text { rotenone, } \\
\text { paraquat, } \\
\text { indole, isp- } \\
\text { 1(qm150), nuo- } \\
6(q m 200) \\
\end{array}$ \\
\hline oac-14 & $\begin{array}{c}\text { O- } \\
\text { acyltransferas } \\
\text { e homolog }\end{array}$ & $\begin{array}{l}\text { transferase activity, } \\
\text { transferring acyl } \\
\text { groups other than } \\
\text { amino-acyl groups }\end{array}$ & 1.24 & 0.085 & $\begin{array}{l}\text { bacterial } \\
\text { infection, } \\
\text { quercetin, } \\
\text { tryptophan, } \\
\text { rotenone, } \\
\text { paraquat, } \\
\text { indole, nuo- } \\
6(q m 200)\end{array}$ \\
\hline F58B4.5 & unknown & unknown & 1.21 & 0.030 & $\begin{array}{c}\text { resveratrol, } \\
\text { quercetin, spg-7 } \\
\text { RNAi, } \\
\text { tryptophan, } \\
\text { isp-1(qm150), } \\
\text { nuo-6(qm200), } \\
\text { paraquat } \\
\text { indole, }\end{array}$ \\
\hline comt-4 & $\begin{array}{l}\text { Catechol-O- } \\
\text { methyl- } \\
\text { transferase }\end{array}$ & $\begin{array}{c}\text { O-methyltransferase } \\
\text { activity }\end{array}$ & 1.17 & 0.030 & $\begin{array}{c}\text { pathogenic } \\
\text { bacteria, } \\
\text { ahr-1(ju145), } \\
\text { quercetin, } \\
\text { rotenone, } \\
\text { paraquat, } \\
\text { isp-1(qm150), } \\
\text { nuo-6(qm200), } \\
\text { indole, aging } \\
\end{array}$ \\
\hline F09C8.1 & $\begin{array}{l}\text { Ortholog of } \\
\text { human }\end{array}$ & $\begin{array}{l}\text { Phospholipase } \\
\text { activity; }\end{array}$ & 1.08 & 0.030 & $\begin{array}{l}\text { ahr-1(ju145), } \\
\text { bacterial } \\
\text { infection, }\end{array}$ \\
\hline
\end{tabular}


Brinkmann et. al

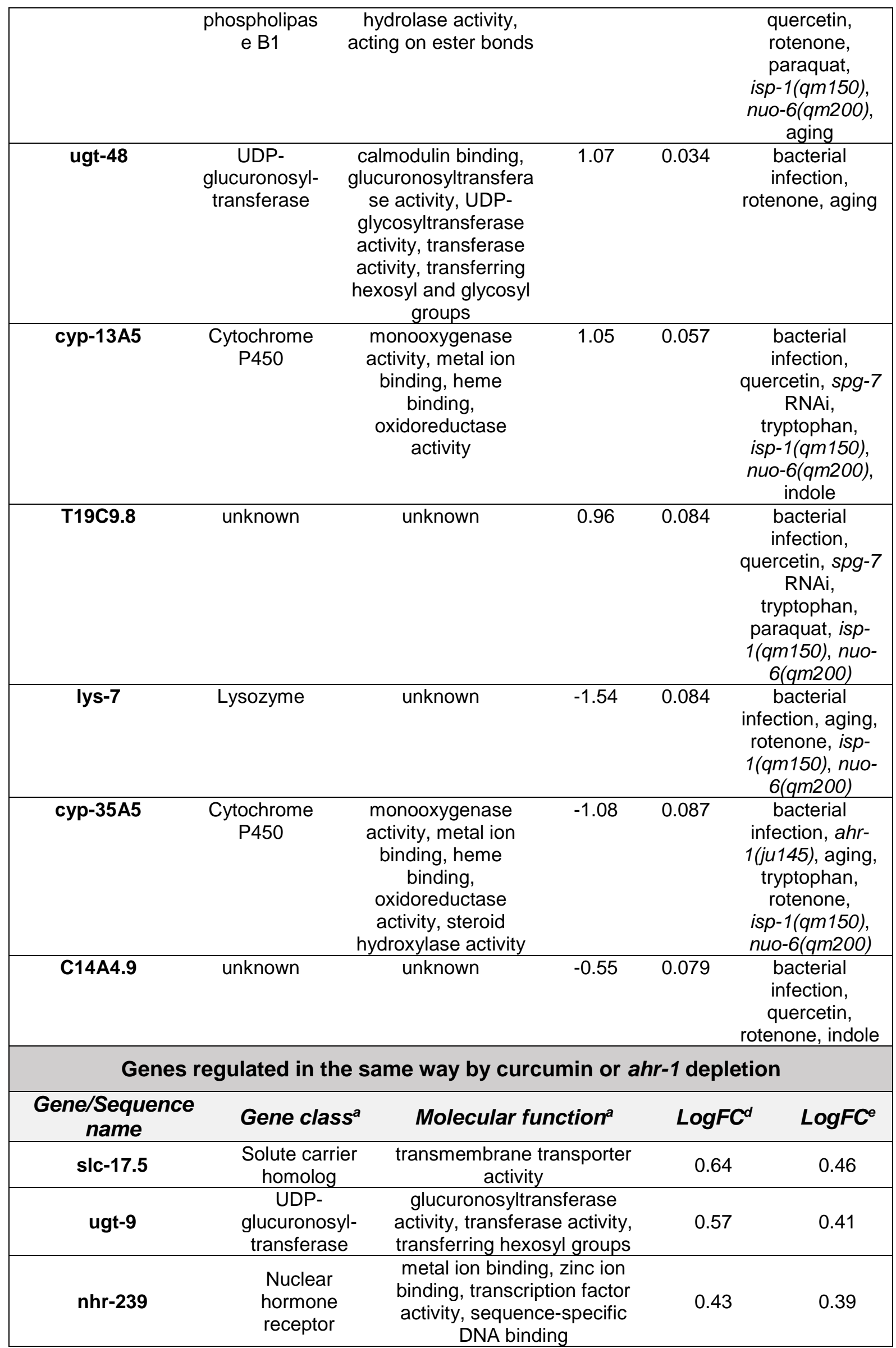


Brinkmann et. al

\begin{tabular}{|ccccc|}
\hline ugt-29 & $\begin{array}{c}\text { UDP- } \\
\text { glucuronosyl- } \\
\text { transferase }\end{array}$ & $\begin{array}{c}\text { glucuronosyltransferase } \\
\text { activity, transferase activity, } \\
\text { transferring hexosyl and } \\
\text { glycosyl groups }\end{array}$ & 0.36 & 0.34 \\
\hline C14A4.9 & unknown & unknown & -0.55 & -0.63 \\
\hline
\end{tabular}

${ }^{a}$ Extracted from Wormbase; 'bogFC: logarithmic fold change; ${ }^{\mathrm{c} A d j . ~ p-v a l u e: ~ a d j u s t e d ~ p-v a l u e ; ~}$ dogarithmic fold change wt curcumin vs. wt DMSO; 'logarithmic fold change ahr-1 DMSO vs. wt DMSO.

A

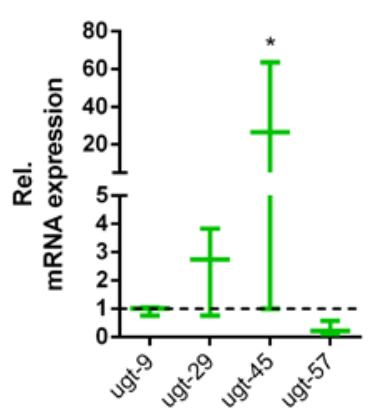

C

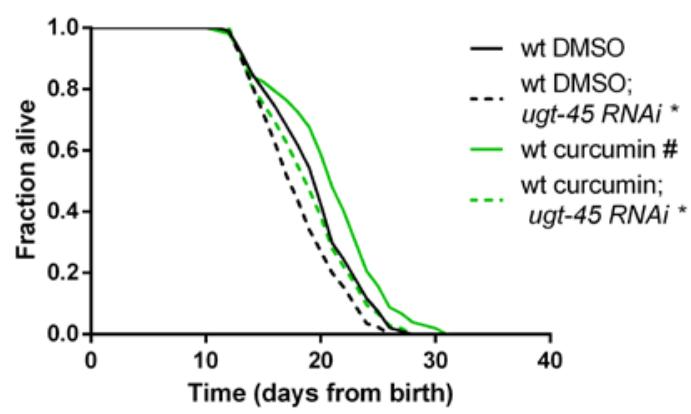

E

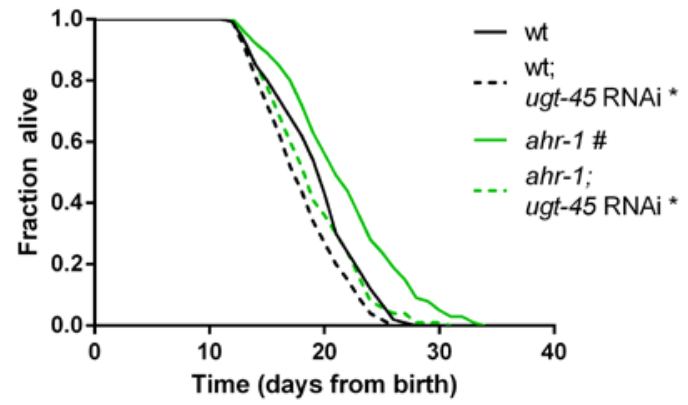

B wt DMSO vs. wt curcumin

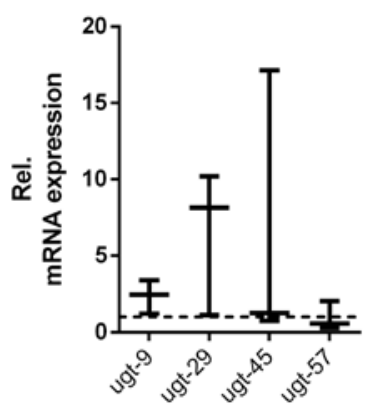

D

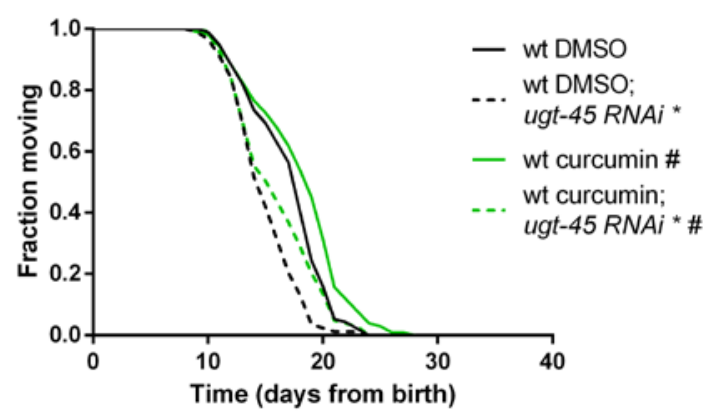

$\mathbf{F}$

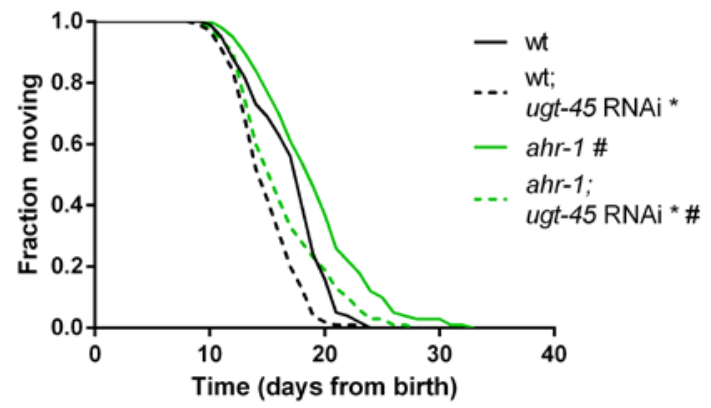

Figure 3. ugt-45 is required for the lifespan extension of curcumin and ahr-1 mutants.

A-B) Gene expression was assessed by qPCR in wt vs. ahr-1 (A) and DMSO- vs. curcumin-treated wt nematodes (B). Boxplots show data of 3 experiments. The expression is shown relative to DMSOtreated wt (indicated as dashed line). Statistical test: 2-Way ANOVA with Sidak's multiple comparisons test, * $p$-value < 0.05 vs. wt, ${ }^{\#} p$-value $<0.05$ vs. DMSO. C-D) Effect of ugt-45 RNAi on curcumin-mediated life-/healthspan extension in the wt. Survival curves show pooled data of 120 worms/condition in 2 replicates. Statistical test: Log-Rank test, "significance vs. DMSO, *significance vs. control RNAi, Bonferroni p-value $<0.05$. E-F) Effect of ugt-45 RNAi on ahr-1-mediated life-/healthspan extension. Survival curves show pooled data of 120 worms/condition in 2 replicates. Statistical test: Log-Rank test, ${ }^{\#}$ significance vs. wt, *significance vs. control RNAi, Bonferroni p-value $<0.05$. 
Brinkmann et. al

\section{AHR-1 and curcumin independently protect against oxidative stress}

240 The beneficial properties of polyphenols are often ascribed to their ability to protect against reactive oxygen species (ROS) (Bors et al., 1990, Sandoval-Acuna et al., 2014). Since AhR is

242 involved in oxidative stress-mediated processes (Wang et al., 2019, Kubli et al., 2019, Shi et 243 al., 2021) we wondered whether curcumin may impact animals' physiology via AhR-regulated 244 antioxidant responses. We observed that ahr-1 mutants produce more mitochondrial(mt)ROS 245 and have a reduced mitochondrial membrane potential (Fig 4A, B), two parameters correlating 246 with longevity (Bazopoulou et al., 2019, Lemire et al., 2009). While consistent with the 247 mitohormesis paradigm ahr-1(ju145) produce slightly more mtROS and live longer, these 248 animals were more sensitive to oxidative stress than the wild-type. Specifically, the detrimental 249 effect induced by juglone and $\mathrm{H}_{2} \mathrm{O}_{2}$ on animals' pumping, motility and survival was significantly 250 stronger in ahr-1(ju145) compared to wild-type (Fig 4C-F). These data suggest that AHR-1 251 depletion has beneficial mitohormetic effects in basal conditions, while its presence is required 252 for oxidative stress protection thus uncoupling two often correlating age-related parameters, 253 namely lifespan and stress resistance. Instead, curcumin significantly improved $\mathrm{H}_{2} \mathrm{O}_{2}$ and 254 juglone resistance in both wild-type and ahr-1 mutants (Fig 4E, F), suggesting that curcumin 255 elicits an ahr-1-independent antioxidant response. Consistent with the uncoupled regulation of 256 lifespan and oxidative stress resistance, ugt-45 silencing did not affect sensitivity to oxidative 257 stress either of ahr-1 mutants or curcumin-treated animals (Fig 4G). Thus, curcumin has pro258 longevity effects via ahr-1 and ugt-45 but protects against oxidative stress through ahr-1259 independent mechanisms. 
Brinkmann et. al

A
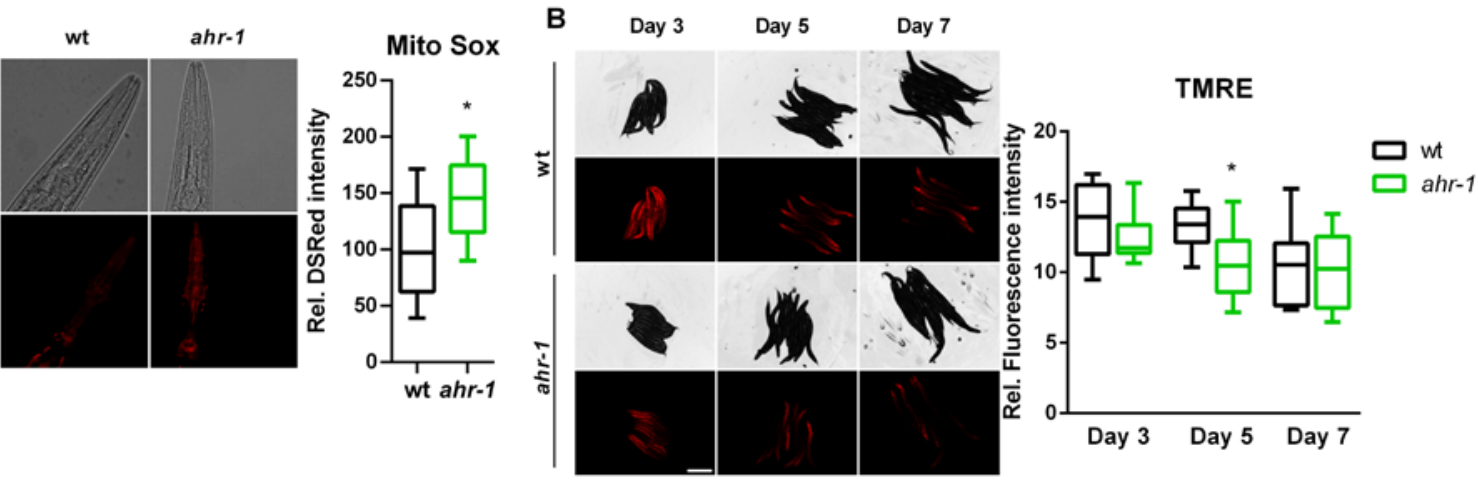

C

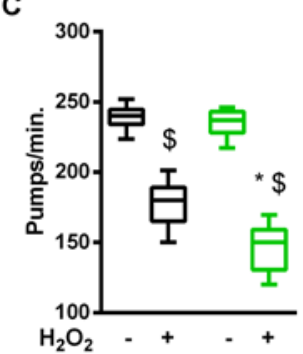

F

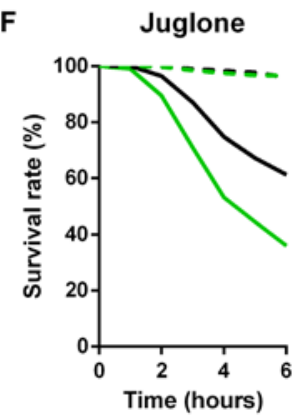

D

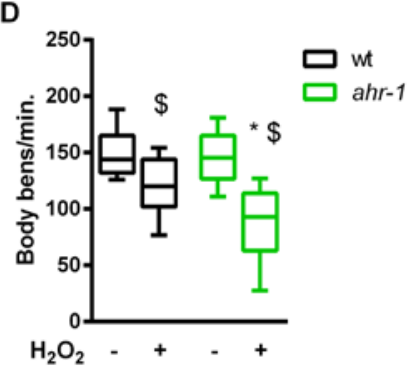

$E$
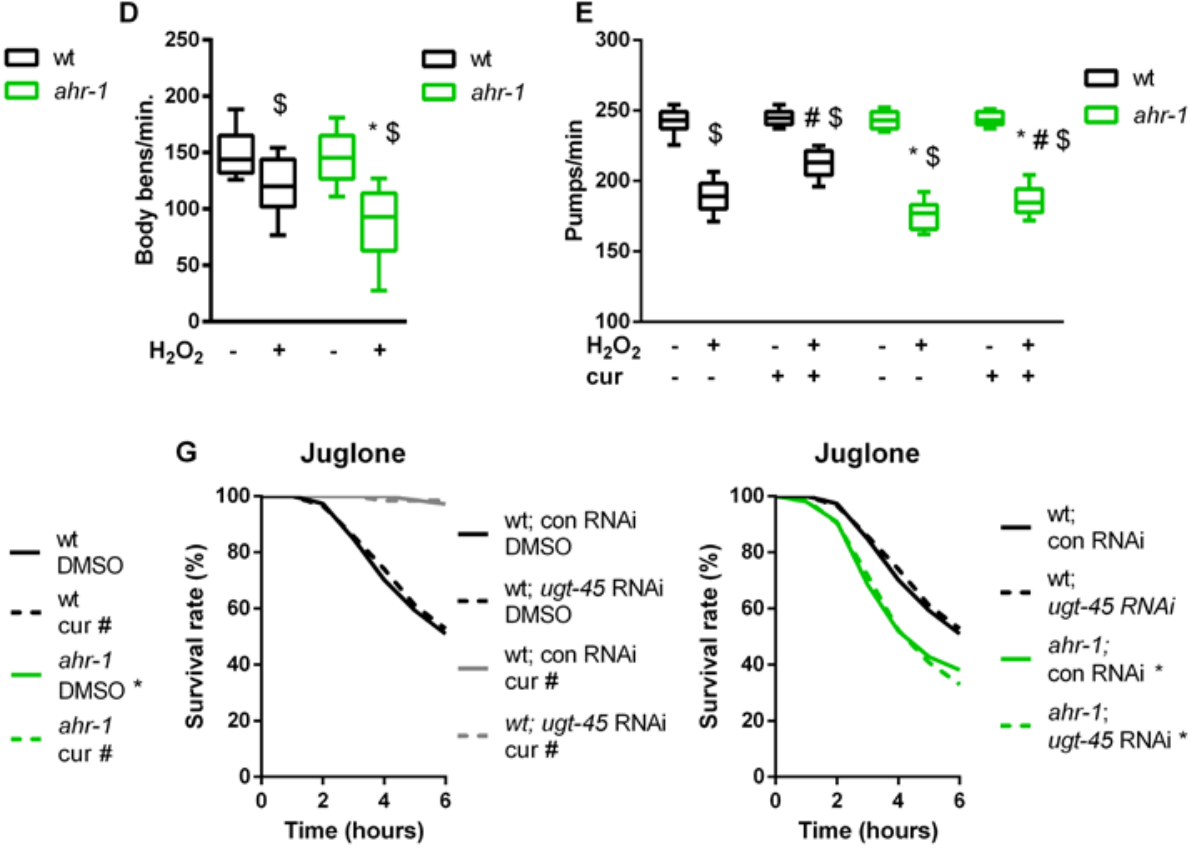

Figure 4. AHR-1 and curcumin independently protect against oxidative stress.

A) Representative images (left) and DSRed intensity quantification (right) in MitoSOX-stained wt or ahr1 nematodes. Boxplots show pooled data from 129-135 worms/condition in 3 experiments. B) The mitochondria membrane potential was assessed by TRME staining in nematodes of indicated ages. Representative images (left) and the quantification of the TMRE fluorescence (right) are presented. Boxplots show pooled data from 3 experiments. C-D) Pharyngeal pumping activity (C) and motility (D) of wt and ahr-1 mutants after $\mathrm{H}_{2} \mathrm{O}_{2}$ treatment. Boxplots show pooled data from 39-54 (C) or 35-36 worms/condition (D) in 3-4 experiments. ${ }^{*}$-value $<0.05$ vs. wt, ${ }^{\$}$-value $<0.05$ vs. control treatment, statistical test: 1-way ANOVA with Tukey's multiple comparisons test. E) Pharyngeal pumping of curcumin-treated nematodes after $\mathrm{H}_{2} \mathrm{O}_{2}$ treatment. Boxplots show pooled data from 32 worms/condition in 2 experiments. ${ }^{*}$ p-value $<0.05$ vs. wt, ${ }^{\# p}$-value $<0.05$ cur vs. DMSO treatment, ${ }^{\$} p$-value $<0.05 \mathrm{H}_{2} \mathrm{O}_{2}$ vs. control statistical test: 2-way ANOVA with Tukey's multiple comparisons test. F) Influence of curcumin on juglone-induced toxicity. Survival curves show pooled data of 500 worms/condition in 20 experiments. *significance ahr-1 vs. wt, "significance curcumin vs. DMSO, Bonferroni p-value $<0.05$. G) Effect of ugt-45 RNAi in curcumin-fed wt and ahr-1 worms. Survival curves show pooled data of 150 worms/condition in 6 experiments. Statistical test: Log-Rank test, *significance ahr-1 vs. wt, "significance curcumin vs. DMSO, Bonferroni p-value $<0.05$. No statistical significance was observed in ugt-45 vs. control RNAi-treated worms. 
Brinkmann et. al

\section{Nrf2/SKN-1 mediates the AhR-independent effects of curcumin}

281 To further evaluate AhR-curcumin crosstalk in additional age-related features, we measured 282 the migratory capacity in human primary EC - a hallmark for vessel functionality, which 283 declines with age (Lahteenvuo and Rosenzweig, 2012) and is reduced by AhR activation 284 (Eckers et al., 2016). In line with the anti-aging activity of ahr-1 suppression and of curcumin, AhR overexpression significantly inhibited, while curcumin increased, the migratory capacity of primary human EC (Fig 5A). Of note, the induction of migratory ability by curcumin was comparable in empty vector- or AhR expression vector-transfected cells (Fig 5A). However, migration of curcumin-treated cells was significantly reduced by AhR overexpression: curcumin induces in empty vector-transfected cells up to 60 migrated cells per high power field, while in AhR overexpressing cells only up to 25 cells per high power field (Fig 5A). These data suggest that the pro-migratory effect of curcumin is modulated by AhR-independent mechanisms but possibly also by a reduction of AhR activity. We next determined intracellular AhR distribution and the expression of cyp1a1 in curcumin-treated human EC. Curcumin did not affect AhRnuclear translocation (Fig 5B) or cyp1a1 expression (Fig 5C).

In search of pathways modulated by curcumin in an AhR-independent manner, we turned back to nematode transcriptomic profiles to find transcription factors regulating genes significantly modulated by loss of ahr-1 or by curcumin treatment in wild-type animals (Table 1). This in silico search identified the redox transcription factor SKN-1, the ortholog of human Nrf2 (nuclear factor erythroid 2-related factor 2), whose activation by curcumin (Ashrafizadeh et al., 2020) has been often reported as a possible mediator of its anti-oxidant activity (Chiu et al., 2020, Li et al., 2021). Accordingly, the prototype C. elegans Nrf2/SKN-1-dependent gene, gst4, is overexpressed in the ahr-1 mutant (Brinkmann et al., 2020b) and induced by curcumin in wild-type and even more in the ahr-1 mutant (Fig 5D). Moreover, curcumin increased stabilization and nuclear translocation of Nrf2 in primary human EC (Fig 5E) and induced the expression of manganese superoxide dismutase (Sod2) - a classic Nrf2 target gene - in the cells transfected with an empty vector or in cells in which AhR has been silenced by shRNA

(Fig 5F). The lack of Sod2 induction by AhR shRNA in EC may be due to a partial reduction 
Brinkmann et. al

308 (50\%) in AhR expression (Fig S3D), which may not be sufficient to trigger the activation of Nrf2 309 or of additional transcription factor (TF), which in C. elegans might concur to the induction of 310 the gst-4 (Detienne et al., 2016) upon complete AhR depletion. Interestingly, Hpgds, a homolog 311 of $C$. elegans gst-4, was significantly increased in the brain of AhR KO mice (Fig S3A) but it is not a target of Nrf2. Further evidence for possible Nrf2/SKN-1 independent signaling activated

313 by ahr-1 depletion is that the activation of the gst-4 by curcumin is completely suppressed by 314 skn-1 RNAi in the C. elegans wild-type, whereas ahr-1 mutants still induce gst-4 despite skn3151 depletion (Fig 5G, H). However, skn-1 RNAi reduced oxidative stress resistance in both wild316 type and ahr-1(ju145) (Fig 5I). Unexpectedly, skn-1 silencing did not affect the juglone 317 resistance of curcumin-treated animals (Fig 5I). Our data reveal a complex scenario whereby 318 curcumin promotes different anti-aging features relying either on AhR-dependent or AhRindependent but Nrf2/SKN-1-dependent (and additional) signaling. 
Brinkmann et. al

A
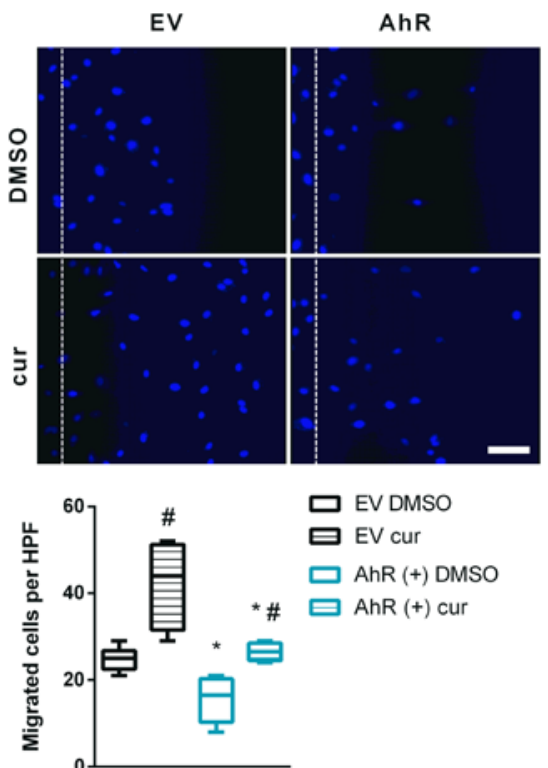

B

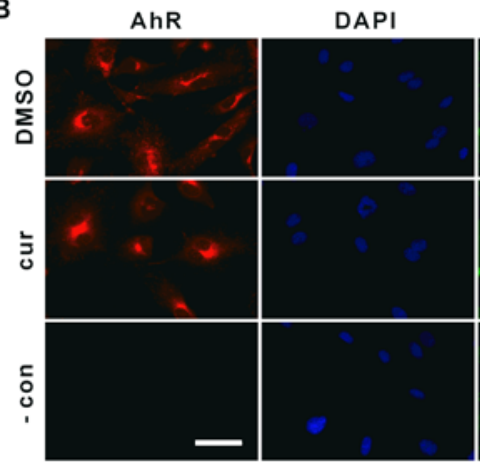

C

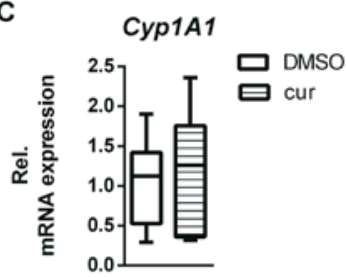

D

E
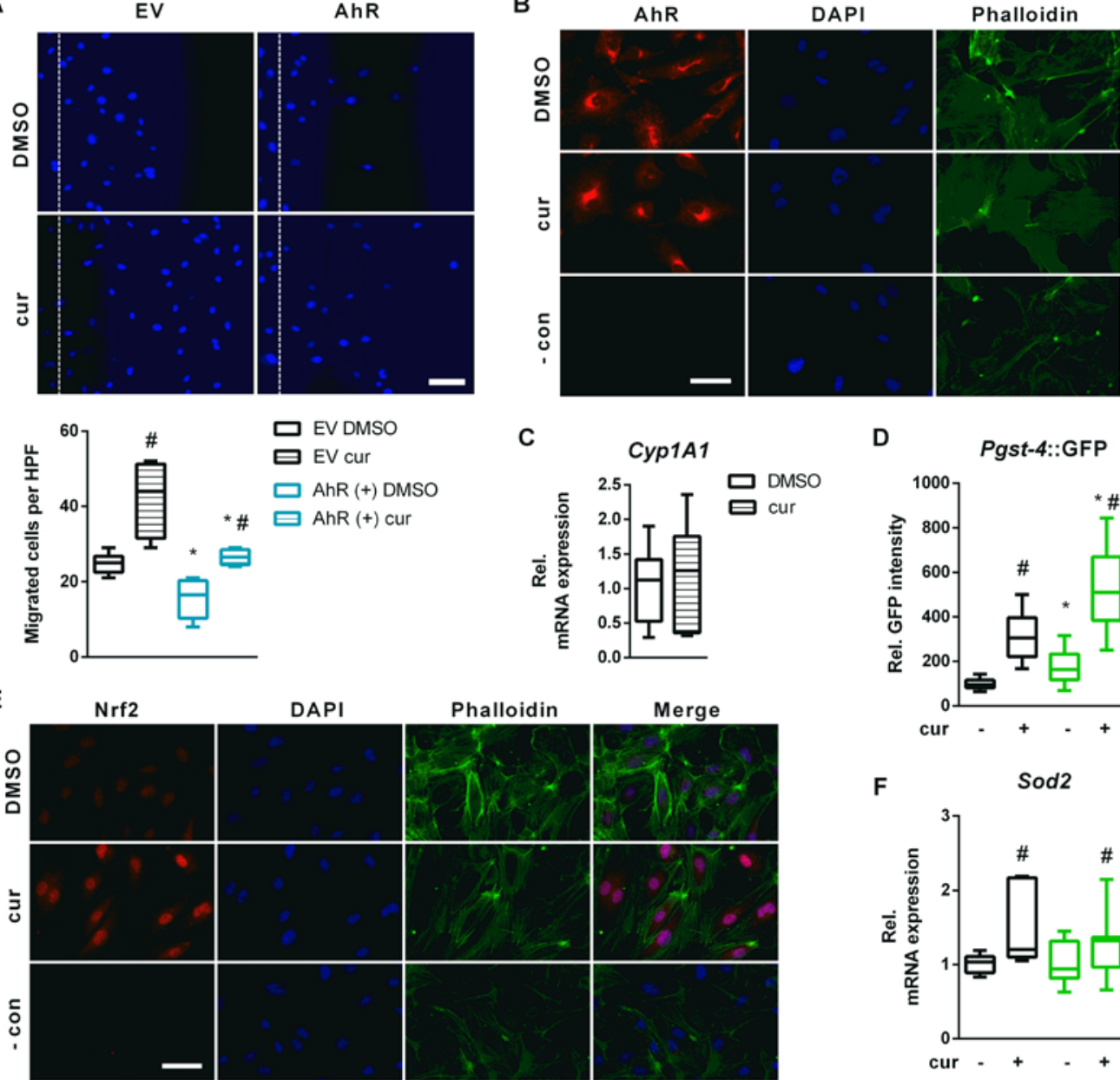

Merge
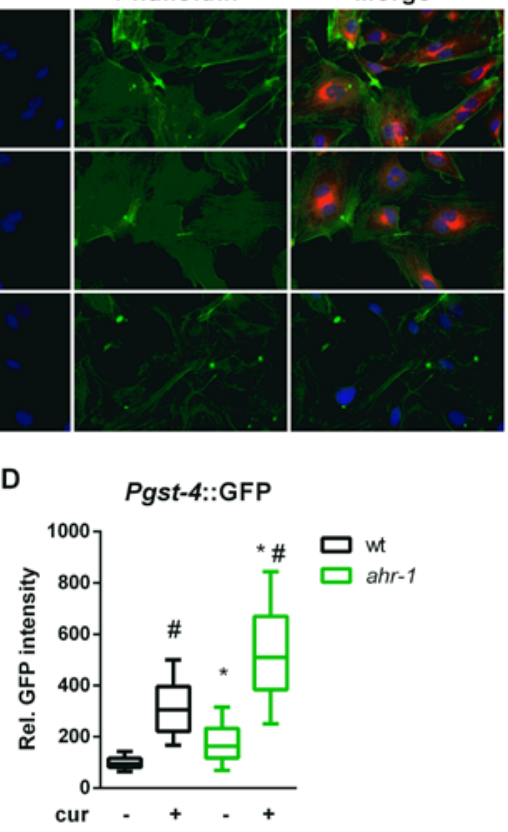

F

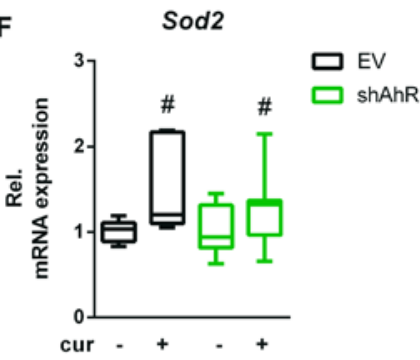

H

G

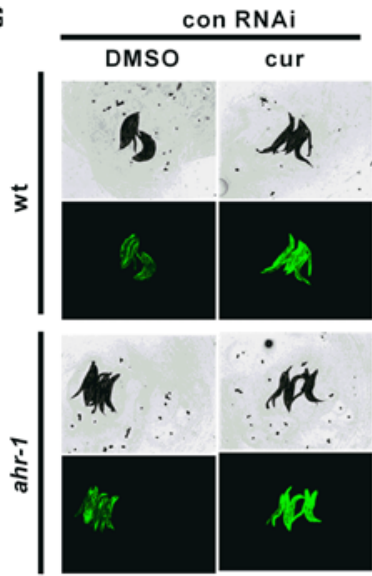

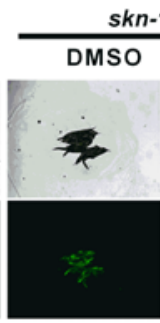

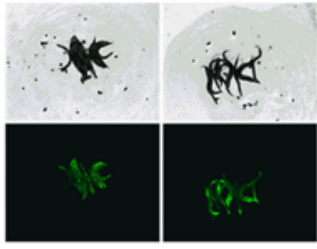

Figure 5. Curcumin activates Nrf2/SKN-1 independent of the AhR.

A) Scratch wound assay in curcumin (cur)- or DMSO-treated human primary EC transfected with an empty vector (EV) or an expression vector for human AhR. Upper panel: representative pictures; the dashed line represents migration start. Scale bar: $100 \mu \mathrm{m}$. Lower panel: quantification; boxplots show data of 4-6 experiments. Statistical test: 1 -way ANOVA, ${ }^{*} p<0.05$ vs. EV, ${ }^{\#} p<0.05$ vs. DMSO. B, C) Human primary EC were treated with cur or DMSO. B) Representative immunostainings: AhR is stained in red, nuclei were visualized with DAPI (blue), the cytoskeleton is counterstained with phalloidin (green), merge shows an overlay of all fluorescence channels. In the negative control (- con) the first antibody was omitted and cells were stained with Alexa 488-coupled phalloidin and DAPI. Scale bar: $50 \mu \mathrm{m}$. C) Relative cyp1a1 expression was assessed by qPCR. Mean expression in the DMSO-treated controls 
bioRxiv preprint doi: https://doi.org/10.1101/2022.02.10.479676; this version posted February 10, 2022. The copyright holder for this preprint (which was not certified by peer review) is the author/funder. All rights reserved. No reuse allowed without permission.

Brinkmann et. al

was set to 1. Boxplots show data of 7 experiments. D) Pgst-4:GFP expression in DMSO- and curcumintreated (cur) wt and ahr-1 worms. Boxplots show pooled data of 118-138 worms/condition in 4 experiments. ${ }^{*} p$-value $<0.05$ vs. wt, ${ }^{*} p$-value $<0.05$ vs. DMSO treatment, statistical test: 1-way ANOVA. E) Representative immunostaining images of human primary EC treated with cur or DMSO: Nrf2 is stained in red, nuclei were visualized with DAPI (blue), the cytoskeleton is counterstained with phalloidin (green), merge shows an overlay of all fluorescence channels. In the negative control (- con) the first antibody was omitted and cells were stained with Alexa 488-coupled phalloidin and DAPI. Scale bar: 50 $\mu \mathrm{m}$. F) Human primary EC were transfected with an empty vector (EV) or an expression vector for an shRNA targeting the human AhR transcript (shAhR). Relative sod2 expression was assessed by qPCR, mean expression in the EV transfected cells was set to 1 . Boxplots show data of 7 experiments. \#p $<0.05$ vs. respective control. G-H) Pgst-4::GFP expression in DMSO- or cur-treated wt and ahr-1 nematodes subjected to control or skn-1 RNAi. Representative images (G) and gst-4-driven GFP quantification $(\mathrm{H})$ are shown. Boxplots show pooled data of 103-189 worms/condition in 4 experiments. I) Juglone stress survival in curcumin- or DMSO-treated wt and ahr-1 nematodes subjected to control or skn-1 RNAi. Kaplan Meier survival curves show pooled data of 100 worms/condition in 4 experiments. Statistical test: Log-Rank test, *significance ahr-1 vs. wt, "\#significance curcumin vs. DMSO, \$significance skn-1 vs. con RNAi, Bonferroni p-value $<0.05$.

\section{Curcumin and pro-oxidants display opposite effects on AHR-1 activity}

Consistent with the anti-aging effect of reduced AhR expression/activity, our data suggest that curcumin may extend the lifespan of $C$. elegans by suppressing AHR-1-regulated pathways through reduction of AHR-1 expression/activity or acting on common downstream signaling pathways. Hence, we tried to quantify AHR-1 activity in C. elegans but numerous attempts to evaluate AHR-1 expression and subcellular localization using antibodies (against mammalian AhR or customized antibodies against CeAhR) or fluorescently-tagged reporters (OP562, UL1709, ZG93), did not give meaningful evidence. Considering that AHR-1 binds to XREs in vitro (Powell-Coffman et al., 1998) we thought to use XRE-driven gene expression as a readout for AHR-1 activity. Thus, we turned to monkey derived Cos7 cells, which do not express endogenous AhR and thus display no endogenous AhR activity (Abnet et al., 1999, Ema et al., 1994) and can be exploited to monitor XRE-driven Luciferase induction as a readout for AHR1 activity (Larigot et al., submitted along with this study). When Cos7 cells were co-transfected with vectors expressing $C$. elegans AhR/ahr-1, ARNT/aha-1, and a luciferase-coupled XREcontaining promoter of the human CYP1A1 gene (Morel and Barouki, 1998) AHR-1 showed low activity in basal (vehicle-treated) conditions. Of note, treatment with curcumin or other nutraceuticals that promote healthy aging in C. elegans, such as lutein (Maglioni et al., 2022) and resveratrol (Regitz et al., 2016, Wood et al., 2004), significantly suppressed AHR-1 activity 
Brinkmann et. al

(Fig 6A-C). Instead, BaP and leflunomide, known AhR activators in mammals, did not affect

AHR-1 activity (Fig 6A-B) at the concentrations we used. Notably, AHR-1 activity was abolished in Cos7 cells transfected with a vector expressing the ahr-1(ju145) allele instead of the wild-type allele (Fig 6A-C), suggesting that ju145 is a true loss-of-function allele and that the measured luciferase intensity is due to functional AHR-1.

We then sought to investigate whether curcumin reduces the activity of AHR-1 by direct binding or indirect modulation. To date, no ligands of $C$. elegans AHR-1 have been identified, and since there is no available information on its LBD, we performed an in silico analysis to characterize it. The two AHR-1 isoforms $1 \mathrm{a}$ and $1 \mathrm{~b}$ were aligned and although different in length their PASB domain sequence is identical. This sequence was then aligned to the PASB domain of Drosophila melanogaster, and to those of two AhRs from vertebrates for which structural models were previously generated, namely mouse (Mus musculus) (Motto et al., 2011), and zebrafish (Danio rerio) (Fraccalvieri et al., 2013) (Fig 6D). The alignment showed clear differences between species with the main peculiarity of invertebrates baring sequence deletions in the most variable region in the PAS domain, corresponding to the flexible region including the helical bundle ( $\mathrm{C} \alpha, \mathrm{Da}$, Ea helices) and the short loops connecting these elements (Fig 6D, E). These deletions could reduce the available space in the binding cavity of these AhRs. We then generated a 3D model of the AHR-1 PASB by Homology Modelling. This model presents the typical PAS fold, but with a shorter Da helix compared to other AhRs. However, the internal cavity has some peculiarities; it contains more hydrophobic residues and is truncated in half by some internal side chains. In particular, H365 and H274 are faced and could form a hydrogen bond in the middle of the cavity; moreover, the Y332, L363, and L302 side-chains could obstruct the cavity, reducing the internal space available for ligands (Fig 6E). This small and truncated cavity most likely does not allow binding of large ligands (e.g., TCDD or curcumin). Similar to the AHR-1 structural model, a model of the zebrafish zfAhR1a showed that the LBD cavity is truncated compared to the TCDD-binding paralogs zfAhR1b and zfAhR2

393 (Fraccalvieri et al., 2013). Small and flexible ligands, like leflunomide bind and activate the 
Brinkmann et. al

zfAhR1a but the leflunomide concentration we tested did not activate AHR-1 in our Cos7 cell system (Fig 6B).

We then wondered whether mutations in amino acids responsible for the small cavity of the LBD might allow classical ligands to activate CeAhR. The CeAhR L363 residue (Fig 6D) corresponds to $\mathrm{A} 375$ in $\mathrm{mAhR} \mathrm{R}^{\mathrm{b}-1}$ and $\mathrm{V} 375$ in $\mathrm{mAhR} \mathrm{R}^{\mathrm{d}}$, and this residue has a major impact on ligand binding (Poland and Glover, 1975). Similarly, T386 of zfAhR1a (Fig 6D), matching to $A 375$ in $m A h R^{b-1}$ and $A 386$ in zfAhR1b and zfAhR2, contributes to the lack of TCDD binding of zfAhR1a and, when mutated to alanine, restores TCDD sensitivity when $\mathrm{Y} 296 \mathrm{H}$ is also introduced (Fraccalvieri et al., 2013). The amino acid Y296 is already a histidine in C. elegans (H274). Thus, we mutated only the leucine at the position L363 in the CeAhR vector to an alanine (L363A) (Fig 6D, E indicated by an arrow). Moreover, we mutated the nearby histidine at position $\mathrm{H} 365$ to glutamine (H365Q), which is Q377 in mice (Fig 6D, E indicated by an arrow) since it likely forms a hydrogen bond with $\mathrm{H} 274$ and might contribute to the small cavity of AHR-1 (Fig 6E). We then tested whether mammalian AhR ligands affect the AHR-1 activity when L363 and H365 are mutated. However, these alterations, instead of restoring response to xenobiotic ligands as in zebrafish (Fraccalvieri et al., 2013), abolished even the basal AHR1 activity, similar to the ju145 allele (Fig 6F). These results show clear differences between the LBDs of $C$. elegans and zebrafish but display that the LBD is fundamental for basal AHR1 activity. Together with previous studies (Jones et al., 2013, Powell-Coffman et al., 1998, Qin and Powell-Coffman, 2004), our results suggest that AHR-1 is unlikely to be involved in the classical xenobiotic-induced transactivation response which thus may not be relevant to ahr1-regulated physiological aging. Instead, plant-derived compounds might exert conserved effects at least in part via suppression of AHR-1-modulated pathways. Our 3D model suggests that curcumin does not modulate AHR-1 activity by binding its LBD. Thus, the suppression of AHR-1 activity by curcumin could be due to its antioxidant effect. Consistent with this possibility, and the increased sensitivity of the C. elegans ahr-1 mutants to oxidative stress, we found that AHR-1 activity is indeed increased by ROS-inducing agents. Namely, Cos7 cells treated with the pro-oxidant rotenone displayed increased AhR activity when transfected with 
bioRxiv preprint doi: https://doi.org/10.1101/2022.02.10.479676; this version posted February 10, 2022. The copyright holder for this preprint (which was not certified by peer review) is the author/funder. All rights reserved. No reuse allowed without permission.

Brinkmann et. al with LBD mutations (Fig 6G, H).

A

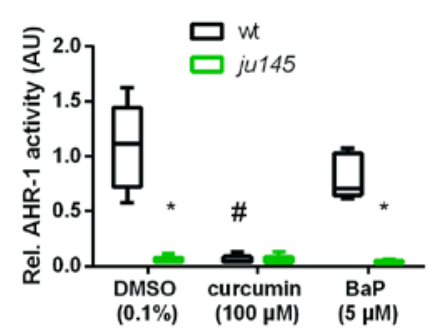

B

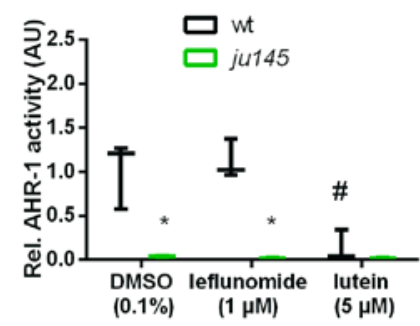

$\mathrm{C}$

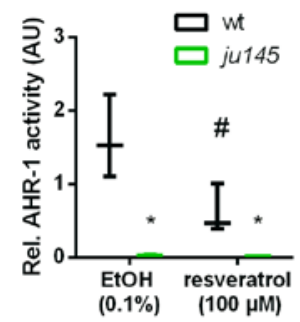

\section{D}

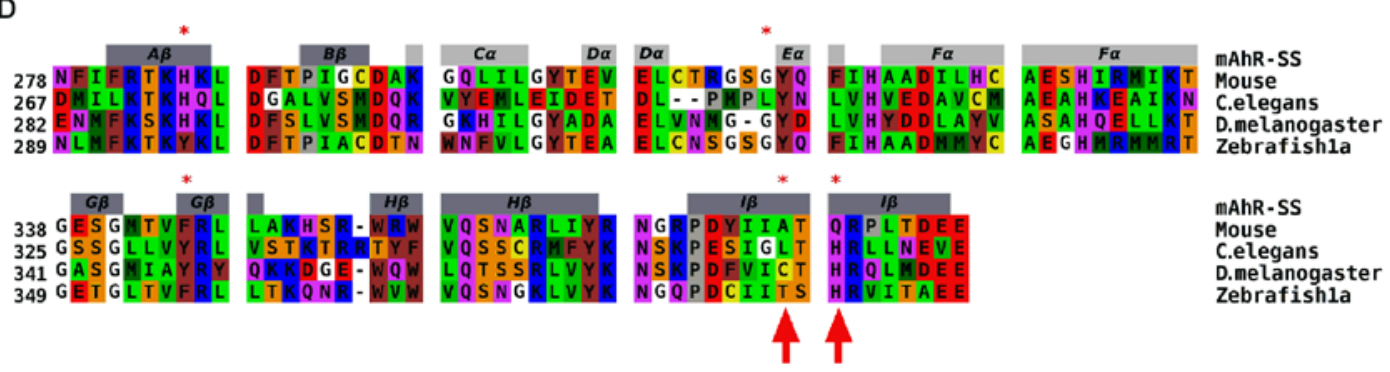

E

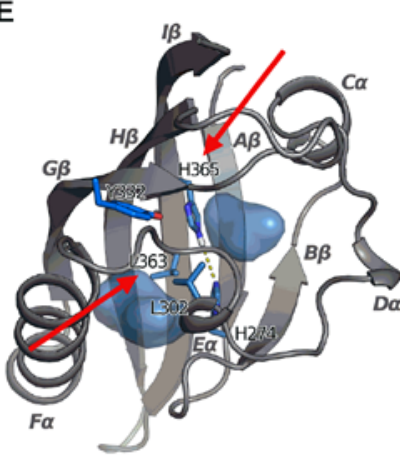

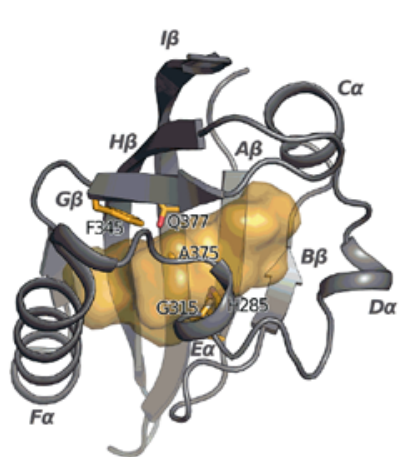

F

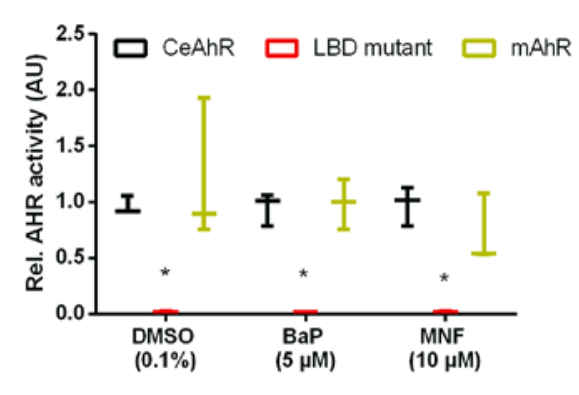

G

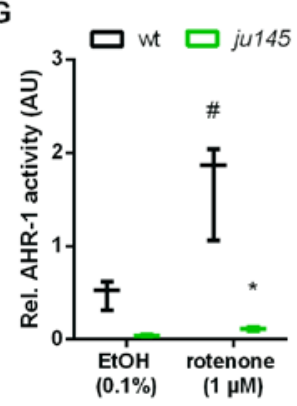

H

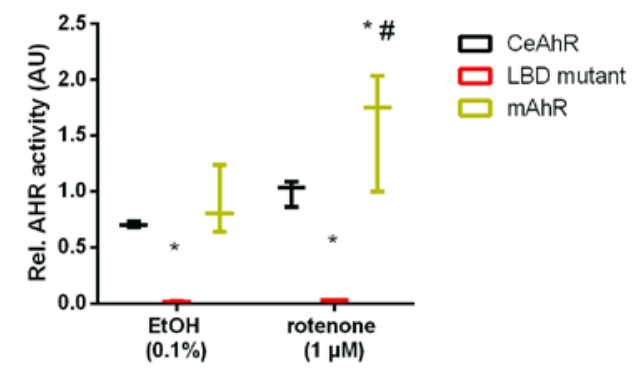

Figure 6. Curcumin and pro-oxidants have opposite effects on AHR-1 activity.

A-C) Evaluation of AHR-1 activity after treatment with the indicated compounds in Cos 7 cells transfected with either wt AHR-1 (wt) or AHR-1 carrying the ju145 point mutation (ju145) and AHA-1 as well as an $\mathrm{XRE}$-inducible luciferase. Boxplots show data of 3-5 experiments. ${ }^{*} \mathrm{p}$-value $<0.05 \mathrm{vs}$. wt, ${ }^{\sharp} \mathrm{p}$-value $<0.05$ vs. DMSO/EtOH, statistical test: 2-way ANOVA and Tukey's multiple comparisons test. D) Alignment of the LBDs from C. elegans, Drosophila, and zebrafish AhRs. Color scheme for residues: red, acidic; blue, basic; purple, polar; yellow, Cys; brown, aromatic; green, hydrophobic; orange, Ser, Thr; gray, Pro; white, Gly. Secondary structures attributed by DSSPcont to the CeAhR PASB are indicated on top (light gray bars for helices and dark gray bars for $\beta$-strands) and labeled according to the PAS domain 
bioRxiv preprint doi: https://doi.org/10.1101/2022.02.10.479676; this version posted February 10, 2022. The copyright holder for this preprint (which was not certified by peer review) is the author/funder. All rights reserved. No reuse allowed without permission.

Brinkmann et. al

nomenclature. Asterisks mark the amino acids likely contributing to the inability of CeAhR to bind big ligands. Amino acids highlighted by an arrow were mutated for the investigation of the LBD function (panels F and H). E) 3D models of the CeAhR (left) and the mAhR (right) PASB domains obtained by Homology Modelling, shown in a cartoon representation. Secondary structures attributed by DSSPcont are labeled according to the PAS domain nomenclature. The colored internal area (blue for CeAhR and yellow for mAhR) defines the molecular surface of the binding cavity identified by CASTp. In the CeAhR model, the amino acids protruding into the binding cavity (asterisks in panel A) are labeled and shown as blue sticks. The mAhR amino acids corresponding to those displayed in the CeAhR model, are labeled and shown as yellow sticks. Amino acids highlighted by an arrow were mutated for studying the LBD function (panels $\mathrm{F}$ and $\mathrm{H}$ ). F) AhR activity in BaP- or MNF-treated Cos7 cells transfected with either AHR-1, an AHR-1 with L363A and H365Q mutations (LBD mutant), or mouse AhR (mAhR), as well as AHA-1 and an XRE-driven luciferase. Boxplots show data of 3 experiments. Statistical analysis: 2-way ANOVA and Tukey's multiple comparisons test. ${ }^{*}$-value $<0.05$ vs. wt, ${ }^{*}$-value $<0.05$ vs. DMSO. G) Effect of rotenone on AhR activity in Cos7 cells transfected with AHR-1 (either wt or ju145) as well as AHA-1 and an XRE-driven luciferase. Boxplots show data of 3 experiments. Statistical analysis: 2-way ANOVA and Tukey's multiple comparisons test. * p-value $<0.05$ vs. wt, ${ }^{p}$-value $<0.05$ vs. DMSO. H) Effect of rotenone on AhR activity in Cos7 cells transfected with either AHR-1, AHR-1 with L363A and H365Q mutations (LBD mutant), or mouse AhR (mAhR). Boxplots show data of 3 experiments. Statistical analysis: 2-way ANOVA with Tukey's multiple comparisons test. * $p$-value $<0.05$ vs. wt/AHR1 , "p-value < 0.05 vs. DMSO/EtOH.

Overall, while CeAhR activation protects against oxidative stress early in life, its decreased expression counteracts aging, and mediates the beneficial anti-aging effect of curcumin. Curcumin may thus help balancing redox TF activation in a context- and time-dependent manner and favor AhR suppression directly through its anti-oxidant effect and/or through activation of Nrf2/SKN-1 (or other TF), which may concurrently mediate the anti-aging activity of curcumin. 
Brinkmann et. al

462

463

464

465

466

467

468

469

470

471

472

473

474

475

476

477

478

479

480

481

482

483

484

485

486

487

488

489

\section{Discussion}

AhR was originally discovered in mammals for its xenobiotic response activity induced upon binding of environmental toxicants or endogenous ligands but modulators not relying on ligandbinding also exist but are much less investigated. C. elegans represents a unique model organism to investigate AhR activities independent of its classical xenobiotic response since CeAhR does not bind prototype AhR ligands (Powell-Coffman et al., 1998, Butler et al., 2001). Using this model we identified an evolutionarily conserved function for AhR in the aging process (Eckers et al., 2016) and showed that some of the mammalian AhR modulators (i.e. bacteria, BaP, UVB) affect aging parameters through AHR-1 in a context-dependent manner (Brinkmann et al., 2020b). Here, we followed up on our previous findings with a more mechanistic investigation of AhR-regulated aging features across species by the dietary polyphenol curcumin. Our combined in vivo, in vitro and in silico analyses revealed a complex scenario: while curcumin promotes anti-aging features in nematodes and human primary EC at least in part in an AhR-dependent manner, its anti-oxidant effects in both species rely on AhR-independent but primarily Nrf2/SKN-1 dependent mechanisms.

Curcumin delayed C. elegans' physiological aging in an AHR-1-dependent manner. In search of possible downstream ahr-1-dependent effectors of curcumin we employed targeted and unbiased approaches and found that the majority of differentially regulated genes upon curcumin treatment are regulated in an AHR-1-dependent manner. Moreover, many of these genes displayed a similar expression pattern in AHR-1-depleted and curcumin-treated animals suggesting curcumin is promoting lifespan extension via suppression of AHR-1 activity. Surprisingly, neither the targeted nor the transcriptomic analysis indicated a major role for classical AhR targets gens such as cyps, which instead were found largely under expressed in neurons (Larigot et al., submitted along with this study). Interestingly, these findings may indicate whole animals transcriptomic may mask neuronal-specific effects of AhR, in this specific case through cyps genes. Among the differentially expressed genes, many belong to phase-II-detoxification enzymes, such as ugt-45, which was increased by both ahr-1 depletion (and in the brain of AhR KO mice) and curcumin treatment and to mediate their lifespan 
Brinkmann et. al

extension. Instead, curcumin and ahr-1 depletion increased the expression of another phaseII-detoxification enzyme, gst-4, through different mechanisms: the former relaying while the latter mainly independent of Nrf2/SKN-1, a classical redox TF inducing gst-4 upon oxidative stress (Kahn et al., 2008). Moreover, while curcumin induces Nrf2/SKN-1-dependent responses in C. elegans (gst-4 expression) and human primary EC (Sod2 expression and migratory capacity), it also protects $C$. elegans against oxidative stress in an SKN-1independent manner. In C. elegans curcumin cannot extend lifespan in the very sick skn1(zu67) mutants (Pecker et al., 1986), while gst-4 can be induced in an SKN-1-independent manner by EGF signaling (Detienne et al., 2016) and a crosstalk between the EGF pathway and the AhR has been reported in mammals (Fritsche et al., 2007).

We also observed an AHR-1-independent effect of curcumin on health-span in nematode models for Huntington's and Parkinson's disease respectively. In these strains curcumin treatment increased the number of protein aggregates to the same extent as AHR-1 deficiency, indicating either a protective effect of the protein aggregation itself and/or curcumin activation of pathways protecting against protein aggregation independently of ahr-1 depletion. The influence of curcumin on protein aggregation is controversial: it was shown to inhibit fibril formation but also to bind pre-fibrillar/oligomeric species of amyloidogenic proteins, thereby accelerating their aggregation and reducing the overall neurotoxicity (Ahmad et al., 2017). Of note, caffeine, which also protects against features of cardiovascular aging (Ale-Agha et al., 2018, Spyridopoulos et al., 2008), also prevents $A \beta$-induced paralysis without decreasing $A \beta$ aggregates but through the activation of the protective Nrf2/SKN-1-dependent pathway (Dostal et al., 2010). It will be important to assess whether the protective effect induced by curcumin or ahr-1 depletion in the $C$. elegans disease models, is mediated by mechanisms promoting the removal of oligomeric/pre-fibrillar species into less toxic aggregates and/or by activation of other mechanisms such as Nrf2/SKN-1, which may concurrently protect against proteotoxicity. Noteworthy, detoxification enzymes may contain both XRE and ARE (antioxidant responsive elements) and an interplay between Nrf2/ARE and AhR/XRE regulated signaling has been described (Kohle and Bock, 2007). It will be thus interesting to clarify how curcumin promotes 
Brinkmann et. al

518 its different beneficial anti-aging effects through the balance between Nrf2 and AhR-regulated 519 signaling.

520 We showed that curcumin inhibits AHR-1 activity. In mammals, it was suggested the AhR 521 inhibitory effect of curcumin is mediated by direct LBD binding (Ciolino et al., 1998) or inhibition 522 of the protein kinase $C$ that phosphorylates AhR (Nishiumi et al., 2007). Another study 523 indicated that the transcriptional activity of the AhR is dependent on cellular redox status and 524 the chromatin structure, which are both influenced by curcumin (Mohammadi-Bardbori et al., 525 2016). While AHR-1 does not bind TCDD, it binds XRE in vitro (Bell and Poland, 2000) but 526 systematic studies, addressing the potential of polyaromatic hydrocarbons, or other 527 mammalian AhR ligands to modulate AHR-1, are missing primarily due to the lack of suitable 528 tools to assess that. Our studies attempt to fill this gap and, exploiting Cos7 cells expressing AHR-1 coupled to luciferase assays (Larigot et al., submitted along with this study) and in silico modeling of $C$. elegans LBD, revealed that curcumin suppresses AHR-1 activity, but likely not 531 by direct LBD binding. The in vitro assay used in our study confirmed CeAhR is not activated 532 through the classical xenobiotics signaling. Yet, it would not reveal activities due to AhR binding 533 to DNA sequences other than the "classical" XRE found in Cyp1a1 such as the 534 polyphenol(quercetin)-responsive XRE found in PON1 (Gouedard et al., 2004, Guyot et al., 2013). Immunostaining in human primary EC also argues against curcumin inducing AhR nuclear translocation, which, along with the promoting effect of the migratory capacity in AhR overexpressing cells, may also indicate that curcumin suppresses AhR activity.

We propose the inhibitory effect of curcumin, rather than relying on AhR binding, involves its 539 antioxidant ability, which may indeed be associated with, or even depend on, the activation of $540 \mathrm{Nrf2/SKN-1.} \mathrm{Mammalian} \mathrm{AhR} \mathrm{is} \mathrm{activated} \mathrm{by} \mathrm{ROS} \mathrm{via} \mathrm{LBD-independent} \mathrm{oxidative} \mathrm{modification}$ 541 (Wang et al., 2019) but our data show that the induction of AHR-1 activity by the pro-oxidant rotenone required the LBD. An indirect mechanism of ROS-mediated AhR activation is the formation of the potent AhR ligand FICZ (Smirnova et al., 2016). Yet, FICZ is a big planar molecule that, according to our in silico model, would not fit the AHR-1 LBD. While the exact 
Brinkmann et. al

546 direct ROS quenching or indirectly via activation of Nrf2 or other antioxidants regulatory genes)

547 remains to be established, this is strongly supported by our findings: AHR-1 is activated by

548 rotenone and ahr-1 mutants display more mtROS, reduced mitochondrial membrane potential

549 and are more sensitive to $\mathrm{H}_{2} \mathrm{O}_{2}$ and juglone as well as to UVB and BaP (Brinkmann et al., 550 2020b), both of which produce ROS (Heck et al., 2003, Wu et al., 2015). In this context, it is

551 interesting to note that ahr-1 mutants display mild alteration of mitochondrial functions, which

552 resemble those of mitohormesis (Ristow and Schmeisser, 2014). This suggests ahr-1 deletion

553 (and possibly curcumin by inhibiting AHR-1) may promote health-span through mild 554 mitochondrial stress, which extends lifespan through detoxification genes similarly modulated 555 by ahr-1 depletion (Herholz et al., 2019, Mao et al., 2019). Moreover, whether, Nrf2/SKN-1 and 556 mitochondria play a role in modulating AHR-1 activity upon curcumin treatment is an interesting 557 possibility that remains to be validated.

558 Overall, our findings suggest the ancestral function of the AhR might be in the regulation of 559 phase-II-enzymes related to antioxidant rather than xenobiotic responses. Opposite to the 560 detrimental effects induced by high levels of ROS, the beneficial effects promoted by AhR561 deficiency may be mediated by mild mitochondria stress and/or mild ROS production 562 (mitohormesis), which also rely on Nrf2/SKN-1. We also provide strong evidence for the 563 interaction between curcumin and the AhR. Curcumin inhibition of AhR signaling is 564 evolutionarily conserved and is likely not mediated by binding to the AhR LBD, but rather 565 through curcumin's ROS-scavenging properties or the activation of Nrf2/SKN-1. The Nrf2 566 signaling pathway can indeed be activated by curcumin in different ways (Ashrafizadeh et al., 567 2020). Finally, our data also showed curcumin promotes anti-aging effects also in an AhR568 independent manner in both $C$. elegans (increased gst-4 expression and oxidative stress 569 resistance) and human primary EC (increased Sod2 expression and migratory capacity), which 570 could also explain the additive effects of curcumin and loss of AHR-1 function on the health571 span of polyQ-expressing animals. Overall, curcumin may help balancing the activity of 572 different transcription factors involved in detoxification/antioxidants responses (suppress AhR 
bioRxiv preprint doi: https://doi.org/10.1101/2022.02.10.479676; this version posted February 10, 2022. The copyright holder for this preprint (which was not certified by peer review) is the author/funder. All rights reserved. No reuse allowed without permission.

Brinkmann et. al

573 and activate Nrf2) in conditions where these are altered (increase AhR and decrease

574 Nrf2/SKN-1), such as aging or age-associated disorders. 
Brinkmann et. al

\section{Materials and Methods}

\section{C. elegans}

\section{C. elegans strains and cultivation}

578 We used the following C. elegans strains: N2 [wild-type], CZ2485 [ahr-1(ju145)], NV38b [ahr579 1(ju145); unc-54p::Q40::YFP], NV38wt [unc-54p::Q40::YFP] (original strain AM141(Morley et 580 al., 2002)), NV42a [unc-54p::alphasynuclein::YFP, ahr-1(ju145)], NV42wt [unc581 54p::alphasynuclein::YFP] (original strain NL5901 (van Ham et al., 2008)), NV35a [ahr582 1(ju145); (pAF15)gst-4p::GFP::NLS], NV35wt [(pAF15)gst-4p::GFP::NLS] (original strain 583 CL2166). For maintenance, worms were kept synchronized by egg lay at $20^{\circ} \mathrm{C}$ on Nematode 584 Growth Media (NGM) plates and fed with E. coli OP50 according to methods described in 585 (Brinkmann et al., 2020b). For the experiments, worms were synchronized on plates 586 supplemented with E. coli HT115(DE3) on plates supplemented with 1 mM IPTG.

587

588 589

590

591

592 plates.

\section{E. coli strains and growth}

594 Bacteria were grown in LB medium at $37^{\circ} \mathrm{C}$ overnight. When using $\mathrm{E}$. coli carrying vectors the 595 LB medium was supplemented with $0.01 \%$ of ampicillin and $0.0005 \%$ of tetracycline. E. coli 596 HT115(L4440), HT115(ugt-45), HT115(skn-1), and OP50 were obtained from the Ahringer 597 C. elegans RNAi library (Kamath and Ahringer, 2003).

\section{Lifespan}


Brinkmann et. al

599 The lifespan analysis was started from a synchronized population of worms, which was 600 transferred to fresh NGM plates daily during the fertile period. After the fertile phase, the 601 animals were transferred every alternate day. Dead, alive, and censored animals were scored during the transferring process. Animals were counted as dead when they did show neither

603

604

605

606

607

608

609

610

611

613

614

615

PolyQ $_{40}$ aggregates were visualized by fluorescence microscopy (100x magnification) in 10movement, nor response to a manual stimulus with a platinum wire, nor pharyngeal pumping activity. Animals with internal hatching (bags), an exploded vulva, or which died desiccated on the wall were censored. The number of dead and censored animals was used for survival analysis in OASIS (Yang et al., 2011) or OASIS 2 (Han et al., 2016). For the calculation of the mean lifespan and the survival curve in OASIS and OASIS 2, the Kaplan Meier estimator was used, and the p-values were calculated using the log-rank test between pooled populations of animals.

\section{Movement/Healthspan}

The movement was set as a parameter for healthy aging, and the phase of the active movement is referred to as healthspan. It was assessed in the populations used for the lifespan assay. Animals, which were either crawling spontaneously or after a manual stimulus, were considered as moving while dead animals or animals without crawling behavior were considered as not moving. Statistical analysis was done as described for lifespan.

\section{Curcumin treatment of $C$. elegans}

Curcumin (Sigma Aldrich, C7727) was dissolved in DMSO (Carl Roth, 4720) in a concentration of $100 \mathrm{mM}$ and supplied to the NGM after autoclaving. The final concentration of curcumin in the media was $100 \mu \mathrm{M}(0.1 \% \mathrm{DMSO})$. Control plates contained 0.1\% DMSO. Worms were treated continuously starting from eggs.

\section{Quantification of polyQ aggregates} days old worms anesthetized with $15 \mathrm{mM}$ sodium azide (Sigma, S2002). To assess the number of aggregates, images were stitched using the Fiji pairwise stitching plugin (Preibisch et al., 
Brinkmann et. al

625

626

627

628

629

630

631

632

633

634

635

636

637

638

639

640

641

642

643

644

645

646

647

648

649

650

2009) to create whole worms and the number of the aggregates was quantified in Fiji (Schindelin et al., 2012) using the plugin "Analyze Particles".

\section{Quantification of $\alpha$-synuclein aggregates}

a-synuclein aggregates in the head muscles of 7-days old worms were visualized by fluorescence microscopy (400x magnification) in worms anesthetized with $15 \mathrm{mM}$ sodium azide (Sigma, S2002). Pictures were segmented using llastik (version 1.3.0) (available on https://www.ilastik.org/) (Sommer et al., 2011). The segmented pictures were used to analyze the number of aggregates in Fiji (Schindelin et al., 2012) using the plugin "Analyze Particles".

\section{Microarray and GO term analysis}

Samples from 5 independent replicates with approximately 1000 3-days old worms per condition were collected, the RNA was extracted and loaded to an Affymetrix Chip. The microarray raw data in the format of CEL were analyzed using the software $\mathrm{R}$ (version 3.4.2) and Bioconductor (Huber et al., 2015). Background correction, normalization, and expression calculation were performed with the oligo package (Carvalho and Irizarry, 2010) and the RMA method. For quality control of the array, the package arrayQualityMetrics_3.34.0 (Kauffmann et al., 2009) was used. Because of the quality measures, sample ahr-1C5 was excluded from further analysis. The differentially expressed genes were identified using the limma package and a linear model and moderated t-statistic with FDR to test for multiple comparisons (Ritchie et al., 2015). A p-value of 0.1 was applied. The differentially expressed genes were analyzed for Gene Ontology term enrichment using Cytoscape (version 3.6.0) (Shannon et al., 2003) with the plugin ClueGo (version 2.5.0) (Bindea et al., 2009). The microarray data can be accessed through the Gene Expression Omnibus accession no. GSE195769.

\section{ROS quantification}

MtROS have been detected in live wt and ahr-1 mutants worms using MitoSOX Red (ThermoFisher Scientific). Nematodes have been synchronized by egg-laying onto IPTG plates using HT115(L4440) bacteria as food. 48 hours later, 50 animals at the L4 stage have 
Brinkmann et. al

651 been transferred onto freshly prepared $10 \mu \mathrm{M}$ MitoSOX Red plates seeded with UV-killed $652 \mathrm{HT} 115(\mathrm{~L} 4440)$. The worms have been incubated in the dark at $20^{\circ} \mathrm{C}$. Following 16 -hour 653 incubation, they have been moved onto new NGM plates spread with live HT115(L4440) for $6541 \mathrm{~h}$ to remove residual dye from the intestines. For imaging, nematodes were mounted onto $6552 \%$ agarose pad slides, anesthetized by adding 10mM levamisole and fixed by ProLong ${ }^{\mathrm{TM}}$ 656 Glass Antifade Mountant (ThermoFisher Scientific). Images were acquired immediately with a 657 Zeiss Axio Imager M1 microscope (Carl Zeiss, Inc.) using a 40X objective and a DsRed Filter. 658 Afterward, the worms head region has been manually selected and the integrated intensity 659 was calculated using the imaging software Fiji (Schindelin et al., 2012).

Tetramethylrhodamine ethyl ester (TMRE) assay

661

662

663

664

665

666

To assess the mitochondrial membrane potential, nematodes were synchronized by egg-laying on IPTG plates seeded with HT115(L4440) bacteria. On the day of the experiment, TMRE was dissolved in DMSO to a concentration of $5 \mathrm{mM}$ and then diluted to $30 \mu \mathrm{M}$ with heat-inactivated $\mathrm{HT} 115(\mathrm{~L} 4440)\left(30 \mathrm{~min}, 65^{\circ} \mathrm{C}\right)$. A total of $150 \mu \mathrm{l}$ of this solution was added per plate and left to dry in the dark for approximately 30 minutes. Sixty adult synchronous worms at 1,3 , or 5 days of adulthood have been picked onto the TMRE plates prepared and left to the stain to absorb for 2 hours in the dark at $20^{\circ} \mathrm{C}$. After staining, worms have been transferred onto IPTG plates seeded with heat-inactivated HT115(L4440) and incubated for $1 \mathrm{~h}$ in the dark at $20^{\circ} \mathrm{C}$, to remove residual dye from the intestines. For imaging, 10 nematodes were mounted onto $2 \%$ agarose pad slides, anesthetized by adding $10 \mathrm{mM}$ levamisole, and fixed by ProLong ${ }^{\mathrm{TM}}$ Glass Antifade Mountant (ThermoFisher Scientific). For each experimental run, 5 slides have been prepared per group. Images were acquired immediately with a Zeiss Axio Imager M1 microscope (Carl Zeiss, Inc.) using a 2.5X objective and a DsRed filter. The fluorescence intensity has been calculated using Fiji (Schindelin et al., 2012).

\section{Pharyngeal pumping rate and motility assay}

N2 and CZ2485 nematodes have been synchronized by bleaching (Shaham, 2006) and the eggs were left to hatch in egg buffer $(118 \mathrm{mM} \mathrm{NaCl}, 48 \mathrm{mM} \mathrm{KCl}, 2 \mathrm{mM} \mathrm{CaCl} 2,2 \mathrm{mM} \mathrm{MgCl}$, 
Brinkmann et. al

67825 mM Hepes, pH 7.3) overnight, on orbital shacking. L1 larvae have been spotted onto NGM 679 supplemented with $1 \mathrm{mM}$ IPTG and containing $0.1 \%$ DMSO or $100 \mu \mathrm{M}$ curcumin. $680 \mathrm{HT} 115(\mathrm{~L} 4440)$ bacteria have been used as food. Young adult worms have been collected with 681 M9 buffer, centrifuged (300 $\mathrm{g} \times 3 \mathrm{~min}$ ), and washed twice to remove bacteria. Worms have 682 been incubated with 0-1 $\mathrm{mM} \mathrm{H}_{2} \mathrm{O}_{2}$ (Sigma-Aldrich, 31642) (100 worms/100 $\mu \mathrm{l}$ ), for 2 hours on 683 orbital shaking. Control worms have been incubated with M9 buffer only. After 2 hours, worms 684 have been moved onto NGM supplemented with $1 \mathrm{mM}$ IPTG and containing 0.1\% DMSO or $685100 \mu \mathrm{M}$ curcumin and seeded with HT115(L4440) bacteria as food. The pharyngeal pumping 686 rate, scored by counting the number of times the terminal bulb of the pharynx contracted over 687 a 1-minute interval (pumps/min), and the motility assay, scored by counting the number of body 688 thrash (body bends/min) in M9 buffer over a 1-minute interval, have been scored from 2 hours up to 20 hours later.

\section{Acute juglone sensitivity assay}

691 N2 and CZ2485 nematodes have been synchronized by egg-laying onto NGM plates with 692 either DMSO or $100 \mu \mathrm{M}$ of curcumin. Plates have been supplemented with $1 \mathrm{mM}$ IPTG and seeded with HT115(L4440) or HT115(ugt-45) bacteria as food. To evaluate the effect of skn-1 RNAi, the worms have been synchronized by egg-laying onto DMSO or curcumin plates seeded with HT115(L4440) bacteria. As nematodes reached the L4 larval stage, they were transferred for $24 \mathrm{~h}$ onto DMSO or curcumin plates seeded with HT115(skn-1) bacteria. Day 1 adult worms (25 worms) have been moved onto fresh NGM plates containing $200 \mu \mathrm{M}$ Juglone and seeded with $25 \mu \mathrm{L}$ of $10 \mathrm{x}$ concentrated bacteria overnight culture. Worm survival under juglone-induced oxidative stress has been checked by touch-provoked movement hourly, for 6 hours. Animals were scored as dead when they failed to respond to touch with a platinum wire pick. Nematodes desiccated on the wall have been censored. The number of dead and censored animals has been scored and the Online Application for Survival analysis OASIS 2 has been employed for survival analysis (Han et al., 2016). 
Brinkmann et. al

NV35wt and NV35a have been synchronized by egg-laying onto NGM plates supplemented with $1 \mathrm{mM}$ IPTG and containing 0.1\% DMSO or $100 \mu \mathrm{M}$ curcumin. HT115(L4440), HT115(ugt45) and HT115(skn-1) bacteria have been used as food. To visualize GFP fluorescence, day 1 adult worms have been anesthetized with $10 \mathrm{mM}$ levamisole hydrochloride solution and mounted on $2 \%$ agarose pads. Images have been immediately acquired with a Zeiss Axio Imager M1 microscope (Carl Zeiss, Inc., 2,5x magnification) and then analyzed using the software CellProfiler. Briefly, images have been processed using a pipeline to segment worms in each image from bright field microscopy and separate them from the background. Then, the integrated GFP intensity has been measured per worm.

\section{Semi-quantitative Real-time PCR (qPCR) in C. elegans}

717 Samples from 3 independent replicates with approximately 1000 3-days old worms per condition were collected and RNA was extracted. After washing and elution, the RNA content 719 was quantified by spectrophotometry, and 1-2 $\mu \mathrm{g}$ of RNA was used for the cDNA synthesis 720 (Omniscript RT Kit (Qiagen, 205111)). Primer pairs are listed in Table S1. For the Real-time 721 qPCR, the cDNA was diluted at 1:20 in $10 \mathrm{mM}$ TRIS (pH 8.0). For the reaction, the qPCR 722 Green Core kit (Jena Biosciences, PCR-333L) or the GoTaq® qPCR kit (Promega, A6001) 723 was used. The samples were run in a MyiQ2 cycler (BioRad), and the expression of each sample was measured in duplicate on the same multi-well plate. The expression was 725 calculated relative to the reference genes act-1 and cdc-42 using the iQ5 software. All data 726 collected were enabled for gene study according to the BioRad user instructions, and the 727 expression was calculated using the normalized expression $\left(\mathrm{ddC}_{\mathrm{T}}\right)$. The efficiency of each 728 primer pair reaction was added for correct quantification of the normalized expression. The 729 efficiency was assessed with 1:20, 1:100, 1:500, and 1:2500 dilutions of the cDNA. From 730 normalized expression values, the fold-change compared to wild-type was calculated for each 731 replicate. 
Brinkmann et. al

\section{Mammalian cells}

\section{Cultivation of Cos7 cells}

734

735

736

737

738

Cos7 cells were cultivated at $37^{\circ} \mathrm{C}$ and $5 \% \mathrm{CO}_{2}$ in Dulbecco's Modified Eagle's Medium (DMEM (Gibco/ ThermoScientific)) with 1\% pyruvate, 1\% Glutamax and 10\% Fetal Bovine Serum (FBS (Gibco/ ThermoScientific)) and additional Penicillin (10.000 Units/ml)/ Streptomycin $(10.000 \mu \mathrm{g} / \mathrm{ml})$. As soon as the cells build a confluent cell lawn, they were detached from the base by using $0.05 \%$ Trypsin/EDTA (Thermo Scientific).

\section{Transfection Plasmids}

We used the following plasmids for the transfection of the Cos7 cells: pcDNA3, pcDNA3-AhR1-VP16, pcDNA3-AhA-1-VP16, pcDNA3-AhR-1(ju145)-VP16, p1A1-FL, phRL-TK. The plasmids are described in (Larigot et al., submitted along with this study). The p1A1-FL plasmid carries an XRE-inducible luciferase, phRL-TK carries a renilla luciferase, and the pcDNA3AhR-1-VP16 and pcDNA3-AhA-1-VP16 carry sequences for the expression of the C. elegans AHR-1 and AHA-1, respectively. For this study, we created pcDNA3-AhR-1(LBD)-VP16 by site-directed mutagenesis of the pcDNA3-AhR-1-VP16 plasmid with the QuikChange II SiteDirected Mutagenesis Kit (Agilent, 200523). The following primer pair was used to create an L to A substitution at L363, and an $\mathrm{H}$ to $\mathrm{Q}$ substitution at $\mathrm{H} 365$ of AHR-1: LBD-F 5'-GAGAGCATCGGCGCGACCCAACGGCTGCTGAACGAG-3' and LBD-R 5'-CTCGTTCAGCAGCCGTTGGGTCGCGCCGATGCTCTC-3'. Super-competent XL1-Blue cells were transformed with the obtained plasmid for amplification. The plasmid sequence was verified by Sanger Sequencing.

\section{Transient transfection of Cos7 cells}

24 hours before transfection 20,000 cells/well were seeded in a 48-well plate in $400 \mu \mathrm{I}$ DMEM $(+10 \%$ FBS + antibiotics $)$ and incubated at $37^{\circ} \mathrm{C}$. Cells were then transfected with the following plasmid concentrations using lipofectamine 2000 (Invitrogen): p1A1-FL (244 ng/well), phRLTK (36 ng/well), pcDNA3-AhA-1-VP16 (5 ng/well), and either pcDNA3-VP16 (10 ng/well), 
Brinkmann et. al

758

759

760

761

762

763

764

765

766

767

768

769

770

771

772

773

774

775

776

777

778

779

780

781

782

783

784

pcDNA3-AhR-1-VP16 (5 ng/well) or pcDNA3-AhR-1(ju145)-VP16 (5 ng/well) as described in (Larigot et al., submitted along with this study). Lipofectamine 2000 was used in a concentration of $1 \mu \mathrm{l} /$ well and pre-incubated with the respective plasmids in DMEM for 20 minutes before use. For the transient transfection, Cos7 cells were incubated with the lipofectamine/plasmid mix for 3 hours in DMEM (+10\% FBS) without antibiotics to avoid antibiotic-induced toxicity. Then, the transfection medium was removed and replaced by $400 \mu \mathrm{l} /$ well DMEM (+10\% FBS + antibiotics). The transfected cells were incubated at $37^{\circ} \mathrm{C}$.

On each plate, 2 wells of cells were not transfected and used for normalization purposes.

\section{Treatment of Cos7 cells}

Stock solutions at concentrations 1000-times higher than the desired treatment concentration were prepared for all of the compounds. Curcumin (Sigma Aldrich), Benzo(a)pyrene (Sigma Aldrich), leflunomide (Sigma Aldrich), and lutein (Sigma Aldrich), were dissolved in DMSO (Carl Roth), while resveratrol (Sigma Aldrich) and rotenone (Sigma Aldrich) were dissolved in ethanol (Carl Roth). 24 hours after transfection the cell culture medium of the cells was replaced with a cell culture medium containing a 1:1000 dilution of the respective compound. The cells were treated for 24 hours before assessing the luciferase activity.

\section{Luciferase assay (AhR activity)}

The AhR transcriptional activity was assessed by measuring the activity of an XRE-driven luciferase (Morel and Barouki, 1998). For this, a Dual-Luciferase Reporter Assay System (Promega, E1960) was used. After a 24-hour treatment, Cos7 cells were washed twice with PBS and then lysed for 15 minutes at RT using the passive lysis buffer included in the DualLuciferase Reporter Assay kit. $20 \mu \mathrm{l}$ of the lyzed cells were placed in a white 96-well plate and used for luminescence measurements. The luciferin (LARII) and renilla (Stop\&Glo) substrates were prepared according to the manufacturer's description. The samples were loaded on a luminometer (EG\&G Berthold microplate Luminometer LB 96V Microluminomat plus) and the substrates were attached to the tubing system of the luminometer. First, $65 \mu$ of LARII was added to each well of the sample, and the luminescence produced by the firefly luciferase was 
Brinkmann et. al

785

786

787

788

789

790

791

792

793

794

795

796

797

798

799

800

801

802

803

804

805

806

807

808

809

810

measured, then $65 \mu \mathrm{l}$ of Stop\&Glo reagent was added and the luminescence produced by the Renilla luciferase was measured. To assess AhR activity from the luminescence measurements, we performed the following post-processing steps: First, the luminescence of non-transfected cells was subtracted from the luminescence of each sample for background correction. In the next step, we normalized the luciferase luminescence to the renilla luminescence of the same sample to eliminate differences in the transfection rate and cell number. Another normalization step to the pcDNA-VP16 transfected cells was performed for each treatment group to remove AhR-independent effects on the XRE-driven luciferase.

\section{Cultivation of primary human EC}

Human primary EC(Lonza) were cultured in complete endothelial basal medium (EBM) (Lonza) supplemented with $1 \mu \mathrm{g} / \mathrm{ml}$ hydrocortisone, $12 \mu \mathrm{g} / \mathrm{ml}$ bovine brain extract, $50 \mu \mathrm{g} / \mathrm{ml}$ gentamicin, $10 \mathrm{ng} / \mathrm{ml}$ human epidermal growth factor, and $10 \%(\mathrm{v} / \mathrm{v})$ fetal calf serum at $37^{\circ} \mathrm{C}$ and $5 \% \mathrm{CO}_{2}$ until the third passage. After detachment with $0.05 \%$ (v/v) Trypsin/EDTA (Thermo Scientific), cells were cultured in $6 \mathrm{~cm}$ culture dishes or 6 well culture plates for at least 18 hours before transfection or treatment.

\section{Transient transfection of EC}

Cells were transfected as described previously (Haendeler et al., 2002). In brief, EC were transfected by using SuperFect ${ }^{\circledR}$ Transfection Reagent (Qiagen, Hilden, Germany) according to the manufacturer's instructions. The overexpression or knockdown of AhR was achieved after $24 \mathrm{~h}$ or $48 \mathrm{~h}$, respectively. The transfection efficiency upon overexpression was approximately $40 \%$.

\section{Scratch wound assay of EC}

For investigation of migratory capacity of EC scratch wound assays were performed as described previously (Ale-Agha et al., 2018). In detail, wounds were set into a cell monolayer with a cell scraper along a trace line. After the injury, non-attached cells were removed by gentle washing. The curcumin treatment was performed directly after the wound was set. 
Brinkmann et. al

811 Curcumin was dissolved in DMSO and used at the final concentration of $7.5 \mu \mathrm{M}$. EC migration 812 was quantified by staining the cells with $5 \mu \mathrm{g} / \mathrm{ml}$ 4', 6-diamidino-2-phenylindole (DAPI; Carl 813 Roth) in PBS for 5 minutes after the cells had been fixed with 4\% (v/v) paraformaldehyde for 81415 minutes at room temperature. Images were taken using a Zeiss AxioVision Observer D1 815 fluorescent microscope using a 200-x magnification. Cells migrated into the wound from the 816 trace line were automatically counted using the particle analysis function of ImageJ $1.52 a$ 817 (Abràmoff et al., 2004) after overlapping nuclei were separated.

819 EC were fixed with $4 \%(v / v)$ paraformaldehyde for 15 minutes at room temperature. After 820 permeabilization and blocking in $0.3 \%(\mathrm{v} / \mathrm{v})$ Triton-X 100 and $3 \%(\mathrm{v} / \mathrm{v})$ normal goat serum in 821 PBS, cells were incubated with a rabbit antibody against AhR (1:100, Abcam) or Nrf2 (clone 822 D1Z9C, 1:100, Cell Signaling Technology) diluted in 1\% (v/v) normal goat serum in PBS overnight at $4{ }^{\circ} \mathrm{C}$. Then, cells were washed with PBS and incubated with an Alexa 594-coupled goat anti-rabbit IgG (1:500, Invitrogen) for 1 hour at room temperature. For actin staining, cells were incubated with Alexa Fluor ${ }^{\mathrm{TM}} 488$ Phalloidin (1:70, Invitrogen) for 20 minutes at room temperature. Nuclei were counterstained with $0.5 \mu \mathrm{g} / \mathrm{ml}$ DAPI in PBS for 5 minutes at room

827 temperature and cells were mounted with ProLong ${ }^{\mathrm{TM}}$ Diamond Antifade Mountant (Invitrogen).

828 Fluorescent images were taken using a Zeiss AxioVision Observer D1 fluorescent microscope, $400 x$ or $200 x$ magnification.

\section{qPCR in cells}

Total cellular RNA was isolated by combining lysis in TRIzol ${ }^{\mathrm{TM}}$ with downstream processing using the RNeasy Mini Kit (Qiagen) according to the manufacturer's instructions. cDNA synthesis was performed using the QuantiTect ${ }^{\circledR}$ Reverse Transcription Kit (Qiagen) with 1

$834 \mu \mathrm{g}$ RNA according to the manufacturer's instructions. Relative transcript levels were 835 determined by pPCR using the 2x SYBR $®$ Green qPCR Master Mix and a Rotor-Gene ${ }^{\circledR} \mathrm{Q}$ 836 thermal cycler (Qiagen). The transcript for the ribosomal protein L32 (rp/32) was used as a 837 reference, relative expression was calculated by the $\Delta \mathrm{C}_{\mathrm{t}}$-method (Pfaffl, 2001). The following 
Brinkmann et. al

838 intron-spanning primer pairs were used: cyp1a1: 5'-TCGCTACCTACCCAACCCTT-3', 5'-

839 TGTGTCAAACCCAGCTCCAA-3'; ahr: 5'-CGTGGGTCAGATGCAGTACA-3', 5'

840 ACCAGGGTCAAAATTGGGCT 3'; sod2: 5'-GCCCTGGAACCTCACATCAA-3'; 5'-

841 AGCAACTCCCCTTTGGGTTC-3'; rp/32: 5'-GTGAAGCCCAAGATCGTCAA-3', 5'-

842 TTGTTGCACATCAGCAGCAC-3'.

\section{Mice}

\section{$844 \quad$ Mouse lines and breeding}

845 Female 8-12 week old "Young" and 18 months old ("old") AHR-deficient B6.129-AHR ${ }^{\mathrm{tm} 1 \mathrm{Bra} / \mathrm{J}}$

846 (Schmidt et al., 1996) (referred to here as AHR-KO) mice were bred as heterozygotes in the 847 IUF's animal facility. Wild-type littermates were used for control. Mice were bred and kept 848 under specific pathogen-free conditions on a 12/12-hour light-dark cycle and received 849 standard chow (ssniff®M-Z, SSNIFF, Soest) ad libitum.

\section{0 qPCR in mice}

851 Total RNA was isolated from organ tissues of three WT and three AHR deficient mice with 852 TriZol®. 400ng of RNA was reverse transcribed using the reverse transcriptase M-MLV 853 (Promega, USA) and random hexamer primers. Gene expression levels were measured in 854 duplicates for each mouse tissue on a Rotor-Gene Q (Qiagen, Hilden, Germany), in $15 \mu \mathrm{l}$ 855 final volume, containing 7.5 $\mu$ l Rotor Gene SybrGreen ${ }^{\text {TM }}$ (Biorad. Feldkirchen, Germany), 1 $856 \mu \mathrm{M}$ of each primer, $1.5 \mu \mathrm{l}$ cDNA and RNase free water. Primer efficiencies were between 90 857 and $146 \%$. See Table S2 for primer sequences and efficiencies. Expression levels were 858 calibrated to the expression of RPS6 as a house-keeping gene in the same sample using the $8592^{-\Delta \Delta C}$ T method (Livak and Schmittgen, 2001).

\section{In situ analyses}


Brinkmann et. al

862 The structural model of $C$. elegans AhR LBD (residues 267-372) was generated by homology 863 modeling. The X-ray structures of the PASB domains of homologous bHLH-PAS family 864 members sharing the highest sequence identity (about 20\%) with the CeAhR PASB were used 865 as templates: the circadian locomotor output cycles kaput (CLOCK, PDB: 4F3L), the neuronal 866 PAS domain-containing protein 3 (NPAS3, PDB: 5SY7), the Hypoxia-inducible factors $2 \alpha$ 867 (HIF2 $\alpha$, PDB: 3H82, 4ZP4, 3F1N) and 1a (HIF1 $\alpha$, PDB: 4H6J). The model was obtained with 868 MODELLER (Fiser et al., 2000, Marti-Renom et al., 2000, Sali and Blundell, 1993). The optimal 869 model was selected from among the 100 generated, based on the best DOPE SCORE (Shen 870 and Sali, 2006). The quality of the models was evaluated using PROCHECK (Laskowski et al., 871 1993). Secondary structures were attributed by DSSPcont (Andersen et al., 2002). The binding 872 cavity within the modeled LBDs was characterized using the CASTp server (Dundas et al., 873 2006). Visualization of the models was accomplished using PYMOL (Schrödinger, 2010).

\section{Statistical analysis}

875 Unless otherwise stated, statistical analyses were performed in GraphPad Prism. For life876 /healthspan assays, statistical analysis was done using OASIS (Han et al., 2016). Statistical 877 analysis of the microarray data was performed in R.

\section{Boxplots}

879 Boxplots were created in GraphPad Prism and show the median (line), 25-75 ${ }^{\text {th }}$ percentile (box) 880 and $10-90^{\text {th }}$ percentile (whiskers). 
Brinkmann et. al

\section{Acknowledgments}

882 Most nematode strains utilized in this work were provided by the Caenorhabditis Genetics 883 Center, funded by the NIH Office of Research Infrastructure Programs (P40 OD010440). We 884 thank Thomas Haarmann-Stemmann (IUF, Düsseldorf) for providing Cos7 cells, Katrin 885 Hochrath (IUF) for advice, René Deenen (University of Düsseldorf) for the performance of the 886 microarray, and Daniel Puchta, and Bo Scherer for expert technical assistance. We further 887 thank Wormbase and the GENiE network funded by the European Cooperation in Science and 888 Technology (COST Action BM1408). N.V. acknowledges funding from the Deutsche 889 Forschungsgemeinschaft (DFG VE366/6-1 and VE366/8-1). V.B. was supported by a Ph.D. 890 scholarship from the Jürgen Manchot Foundation. J.A. and J.H. acknowledge funding from the 891 Deutsche Forschungsgemeinschaft: IRTG1902-P1 and IRTG1902-P2.

892 
Brinkmann et. al

\section{Author Contributions}

894 Conceptualization: N.V.

895 Formal analysis: V.B., A.S., N.V.

896 Funding acquisition: V.B., N.V.

897 Investigation: V.B., L.T., M.R., A.H., J.K, L.L., S.W.

898 Supervision: N.V.

899 Resources: R.M., X.C., C.E., J.A., J.H., N.V.

900 Visualization: V.B.

901 Writing -original draft-: V.B., N.V.

902 Writing -review and editing-: R.M., A.S., C.E. 
bioRxiv preprint doi: https://doi.org/10.1101/2022.02.10.479676; this version posted February 10, 2022. The copyright holder for this preprint (which was not certified by peer review) is the author/funder. All rights reserved. No reuse allowed without permission.

Brinkmann et. al

\section{Declaration of interests}

904 The authors declare no competing interests.

905 
bioRxiv preprint doi: https://doi.org/10.1101/2022.02.10.479676; this version posted February 10, 2022. The copyright holder for this preprint (which was not certified by peer review) is the author/funder. All rights reserved. No reuse allowed without permission.

Brinkmann et. al

\section{References}

AARNIO, V., STORVIK, M., LEHTONEN, M., ASIKAINEN, S., REISNER, K., CALLAWAY, J., RUDGALVYTE, M., LAKSO, M. \& WONG, G. 2010. Fatty acid composition and gene expression profiles are altered in aryl hydrocarbon receptor-1 mutant Caenorhabditis elegans. Comp Biochem Physiol C Toxicol Pharmacol, 151, 318-24.

ABEL, J. \& HAARMANN-STEMMANN, T. 2010. An introduction to the molecular basics of aryl hydrocarbon receptor biology. Biol Chem, 391, 1235-48.

ABNET, C. C., TANGUAY, R. L., HEIDEMAN, W. \& PETERSON, R. E. 1999. Transactivation activity of human, zebrafish, and rainbow trout aryl hydrocarbon receptors expressed in COS-7 cells: greater insight into species differences in toxic potency of polychlorinated dibenzo-p-dioxin, dibenzofuran, and biphenyl congeners. Toxicol Appl Pharmacol, 159, 41-51.

ABRÀMOFF, M. D., MAGALHÃES, P. J. \& RAM, S. J. 2004. Image Processing with ImageJ. Biophotonics International, 11, 36-42.

AGGARWAL, B. B. \& HARIKUMAR, K. B. 2009. Potential therapeutic effects of curcumin, the antiinflammatory agent, against neurodegenerative, cardiovascular, pulmonary, metabolic, autoimmune and neoplastic diseases. Int J Biochem Cell Biol, 41, 40-59.

AHMAD, B., BORANA, M. S. \& CHAUDHARY, A. P. 2017. Understanding curcumin-induced modulation of protein aggregation. Int J Biol Macromol, 100, 89-96.

ALAVEZ, S., VANTIPALLI, M. C., ZUCKER, D. J., KLANG, I. M. \& LITHGOW, G. J. 2011. Amyloid-binding compounds maintain protein homeostasis during ageing and extend lifespan. Nature, 472, 226-9.

ALE-AGHA, N., GOY, C., JAKOBS, P., SPYRIDOPOULOS, I., GONNISSEN, S., DYBALLA-RUKES, N., AUFENVENNE, K., VON AMELN, F., ZUREK, M., SPANNBRUCKER, T., ECKERMANN, O., JAKOB, S., GORRESSEN, S., ABRAMS, M., GRANDOCH, M., FISCHER, J. W., KOHRER, K., DEENEN, R., UNFRIED, K., ALTSCHMIED, J. \& HAENDELER, J. 2018. CDKN1B/p27 is localized in mitochondria and improves respiration-dependent processes in the cardiovascular systemNew mode of action for caffeine. PLOS Biol, 16, e2004408.

ANDERSEN, C. A., PALMER, A. G., BRUNAK, S. \& ROST, B. 2002. Continuum secondary structure captures protein flexibility. Structure, 10, 175-84.

ASHIDA, H., FUKUDA, I., YAMASHITA, T. \& KANAZAWA, K. 2000. Flavones and flavonols at dietary levels inhibit a transformation of aryl hydrocarbon receptor induced by dioxin. FEBS Lett, 476, 213-7.

ASHRAFIZADEH, M., AHMADI, Z., MOHAMMADINEJAD, R., FARKHONDEH, T. \& SAMARGHANDIAN, S. 2020. Curcumin Activates the Nrf2 Pathway and Induces Cellular Protection Against Oxidative Injury. Curr Mol Med, 20, 116-133.

BABA, T., SHIMA, Y., OWAKI, A., MIMURA, J., OSHIMA, M., FUJII-KURIYAMA, Y. \& MOROHASHI, K. I. 2008. Disruption of aryl hydrocarbon receptor $(A h R)$ induces regression of the seminal vesicle in aged male mice. Sex Dev, 2, 1-11.

BAZOPOULOU, D., KNOEFLER, D., ZHENG, Y., ULRICH, K., OLESON, B. J., XIE, L., KIM, M., KAUFMANN, A., LEE, Y. T., DOU, Y., CHEN, Y., QUAN, S. \& JAKOB, U. 2019. Developmental ROS individualizes organismal stress resistance and lifespan. Nature, 576, 301-305.

BELL, D. R. \& POLAND, A. 2000. Binding of aryl hydrocarbon receptor (AhR) to AhR-interacting protein. The role of hsp90. J Biol Chem, 275, 36407-14.

BINDEA, G., MLECNIK, B., HACKL, H., CHAROENTONG, P., TOSOLINI, M., KIRILOVSKY, A., FRIDMAN, W. H., PAGES, F., TRAJANOSKI, Z. \& GALON, J. 2009. ClueGO: a Cytoscape plug-in to decipher functionally grouped gene ontology and pathway annotation networks. Bioinformatics, 25, 1091-3.

BORS, W., HELLER, W., MICHEL, C. \& SARAN, M. 1990. Flavonoids as antioxidants: determination of radical-scavenging efficiencies. Methods Enzymol, 186, 343-55. 
bioRxiv preprint doi: https://doi.org/10.1101/2022.02.10.479676; this version posted February 10, 2022. The copyright holder for this preprint (which was not certified by peer review) is the author/funder. All rights reserved. No reuse allowed without permission.

Brinkmann et. al

BRINKMANN, V., ALE-AGHA, N., HAENDELER, J. \& VENTURA, N. 2020a. The Aryl Hydrocarbon Receptor (AhR) in the Aging Process: Another Puzzling Role for This Highly Conserved Transcription Factor. Frontiers in Physiology, 10.

BRINKMANN, V., SCHIAVI, A., SHAIK, A., PUCHTA, D. R. \& VENTURA, N. 2020b. Dietary and environmental factors have opposite AhR-dependent effects on C. elegans healthspan. Aging (Albany NY), 12.

BUTLER, R. A., KELLEY, M. L., POWELL, W. H., HAHN, M. E. \& VAN BENEDEN, R. J. 2001. An aryl hydrocarbon receptor (AHR) homologue from the soft-shell clam, Mya arenaria: evidence that invertebrate AHR homologues lack 2,3,7,8-tetrachlorodibenzo-p-dioxin and betanaphthoflavone binding. Gene, 278, 223-34.

CAESAR, I., JONSON, M., NILSSON, K. P., THOR, S. \& HAMMARSTROM, P. 2012. Curcumin promotes Abeta fibrillation and reduces neurotoxicity in transgenic Drosophila. PLoS One, 7, e31424.

CARVALHO, B. S. \& IRIZARRY, R. A. 2010. A framework for oligonucleotide microarray preprocessing. Bioinformatics, 26, 2363-7.

CHIU, H. F., VENKATAKRISHNAN, K. \& WANG, C. K. 2020. The role of nutraceuticals as a complementary therapy against various neurodegenerative diseases: A mini-review. $J$ Tradit Complement Med, 10, 434-439.

CHOI, H., CHUN, Y. S., SHIN, Y. J., YE, S. K., KIM, M. S. \& PARK, J. W. 2008. Curcumin attenuates cytochrome P450 induction in response to 2,3,7,8-tetrachlorodibenzo-p-dioxin by ROSdependently degrading AhR and ARNT. Cancer Sci, 99, 2518-24.

CIOLINO, H. P., DASCHNER, P. J., WANG, T. T. \& YEH, G. C. 1998. Effect of curcumin on the aryl hydrocarbon receptor and cytochrome P450 1A1 in MCF-7 human breast carcinoma cells. Biochem Pharmacol, 56, 197-206.

DENISON, M. S., PANDINI, A., NAGY, S. R., BALDWIN, E. P. \& BONATI, L. 2002. Ligand binding and activation of the Ah receptor. Chem Biol Interact, 141, 3-24.

DETIENNE, G., VAN DE WALLE, P., DE HAES, W., SCHOOFS, L. \& TEMMERMAN, L. 2016. SKN-1independent transcriptional activation of glutathione S-transferase 4 (GST-4) by EGF signaling. Worm, 5, e1230585.

DIANI-MOORE, S., RAM, P., LI, X., MONDAL, P., YOUN, D. Y., SAUVE, A. A. \& RIFKIND, A. B. 2010. Identification of the aryl hydrocarbon receptor target gene TiPARP as a mediator of suppression of hepatic gluconeogenesis by 2,3,7,8-tetrachlorodibenzo-p-dioxin and of nicotinamide as a corrective agent for this effect. J Biol Chem, 285, 38801-10.

DOSTAL, V., ROBERTS, C. M. \& LINK, C. D. 2010. Genetic mechanisms of coffee extract protection in a Caenorhabditis elegans model of beta-amyloid peptide toxicity. Genetics, 186, 857-66.

DUNDAS, J., OUYANG, Z., TSENG, J., BINKOWSKI, A., TURPAZ, Y. \& LIANG, J. 2006. CASTp: computed atlas of surface topography of proteins with structural and topographical mapping of functionally annotated residues. Nucleic Acids Res, 34, W116-8.

ECKERS, A., JAKOB, S., HEISS, C., HAARMANN-STEMMANN, T., GOY, C., BRINKMANN, V., CORTESEKROTT, M. M., SANSONE, R., ESSER, C., ALE-AGHA, N., ALTSCHMIED, J., VENTURA, N. \& HAENDELER, J. 2016. The aryl hydrocarbon receptor promotes aging phenotypes across species. Sci Rep, 6, 19618.

EMA, M., OHE, N., SUZUKI, M., MIMURA, J., SOGAWA, K., IKAWA, S. \& FUJII-KURIYAMA, Y. 1994.

Dioxin binding activities of polymorphic forms of mouse and human arylhydrocarbon receptors. J Biol Chem, 269, 27337-43.

FERNANDEZ-SALGUERO, P., PINEAU, T., HILBERT, D. M., MCPHAIL, T., LEE, S. S., KIMURA, S., NEBERT, D. W., RUDIKOFF, S., WARD, J. M. \& GONZALEZ, F. J. 1995. Immune system impairment and hepatic fibrosis in mice lacking the dioxin-binding Ah receptor. Science, 268, 722-6.

FERNANDEZ-SALGUERO, P. M., WARD, J. M., SUNDBERG, J. P. \& GONZALEZ, F. J. 1997. Lesions of arylhydrocarbon receptor-deficient mice. Vet Pathol, 34, 605-14.

FISER, A., DO, R. K. \& SALI, A. 2000. Modeling of loops in protein structures. Protein Sci, 9, 1753-73. FLEENOR, B. S., SINDLER, A. L., MARVI, N. K., HOWELL, K. L., ZIGLER, M. L., YOSHIZAWA, M. \& SEALS, D. R. 2013. Curcumin ameliorates arterial dysfunction and oxidative stress with aging. Exp Gerontol, 48, 269-76. 
bioRxiv preprint doi: https://doi.org/10.1101/2022.02.10.479676; this version posted February 10, 2022. The copyright holder for this preprint (which was not certified by peer review) is the author/funder. All rights reserved. No reuse allowed without permission.

Brinkmann et. al

1008

1009

1010

1011

1012

1013

1014

1015

1016

1017

1018

1019

1020

1021

1022

1023

1024

1025

1026

1027

1028

1029

1030

1031

1032

1033

1034

1035

1036

1037

1038

1039

1040

1041

1042

1043

1044

1045

1046

1047

1048

1049

1050

1051

1052

1053

1054

1055

1056

1057

1058

1059

1060

FRACCALVIERI, D., SOSHILOV, A. A., KARCHNER, S. I., FRANKS, D. G., PANDINI, A., BONATI, L., HAHN, M. E. \& DENISON, M. S. 2013. Comparative analysis of homology models of the AH receptor ligand binding domain: verification of structure-function predictions by site-directed mutagenesis of a nonfunctional receptor. Biochemistry, 52, 714-25.

FRITSCHE, E., SCHAFER, C., CALLES, C., BERNSMANN, T., BERNSHAUSEN, T., WURM, M., HUBENTHAL, U., CLINE, J. E., HAJIMIRAGHA, H., SCHROEDER, P., KLOTZ, L. O., RANNUG, A., FURST, P., HANENBERG, H., ABEL, J. \& KRUTMANN, J. 2007. Lightening up the UV response by identification of the arylhydrocarbon receptor as a cytoplasmatic target for ultraviolet $B$ radiation. Proc Natl Acad Sci U S A, 104, 8851-6.

GAO, D., WU, M., WANG, C., WANG, Y. \& ZUO, Z. 2015. Chronic exposure to low benzo[a]pyrene level causes neurodegenerative disease-like syndromes in zebrafish (Danio rerio). Aquat Toxicol, $167,200-8$.

GOUEDARD, C., BAROUKI, R. \& MOREL, Y. 2004. Dietary polyphenols increase paraoxonase 1 gene expression by an aryl hydrocarbon receptor-dependent mechanism. Mol Cell Biol, 24, 520922.

GUTIERREZ-VAZQUEZ, C. \& QUINTANA, F. J. 2018. Regulation of the Immune Response by the Aryl Hydrocarbon Receptor. Immunity, 48, 19-33.

GUYOT, E., CHEVALLIER, A., BAROUKI, R. \& COUMOUL, X. 2013. The AhR twist: ligand-dependent AhR signaling and pharmaco-toxicological implications. Drug Discov Today, 18, 479-86.

HAENDELER, J., HOFFMANN, J., TISCHLER, V., BERK, B. C., ZEIHER, A. M. \& DIMMELER, S. 2002. Redox regulatory and anti-apoptotic functions of thioredoxin depend on S-nitrosylation at cysteine 69. Nat Cell Biol, 4, 743-9.

HAHN, M. E. 2002. Aryl hydrocarbon receptors: diversity and evolution. Chem Biol Interact, 141, 13160.

HAHN, M. E., KARCHNER, S. I., SHAPIRO, M. A. \& PERERA, S. A. 1997. Molecular evolution of two vertebrate aryl hydrocarbon (dioxin) receptors (AHR1 and AHR2) and the PAS family. Proc Natl Acad Sci U S A, 94, 13743-8.

HAN, S. K., LEE, D., LEE, H., KIM, D., SON, H. G., YANG, J. S., LEE, S. V. \& KIM, S. 2016. OASIS 2: online application for survival analysis 2 with features for the analysis of maximal lifespan and healthspan in aging research. Oncotarget, 7, 56147-56152.

HANIEH, H. 2014. Toward understanding the role of aryl hydrocarbon receptor in the immune system: current progress and future trends. Biomed Res Int, 2014, 520763.

HECK, D. E., VETRANO, A. M., MARIANO, T. M. \& LASKIN, J. D. 2003. UVB light stimulates production of reactive oxygen species: unexpected role for catalase. J Biol Chem, 278, 22432-6.

HERHOLZ, M., CEPEDA, E., BAUMANN, L., KUKAT, A., HERMELING, J., MACIEJ, S., SZCZEPANOWSKA, K., PAVLENKO, V., FROMMOLT, P. \& TRIFUNOVIC, A. 2019. KLF-1 orchestrates a xenobiotic detoxification program essential for longevity of mitochondrial mutants. Nat Commun, 10, 3323.

HUANG, S., SHUI, X., HE, Y., XUE, Y., LI, J., LI, G., LEI, W. \& CHEN, C. 2015. AhR expression and polymorphisms are associated with risk of coronary arterial disease in Chinese population. Sci Rep, 5, 8022.

HUANG, X., POWELL-COFFMAN, J. A. \& JIN, Y. 2004. The AHR-1 aryl hydrocarbon receptor and its cofactor the AHA-1 aryl hydrocarbon receptor nuclear translocator specify GABAergic neuron cell fate in C. elegans. Development, 131, 819-28.

HUBER, W., CAREY, V. J., GENTLEMAN, R., ANDERS, S., CARLSON, M., CARVALHO, B. S., BRAVO, H. C., DAVIS, S., GATTO, L., GIRKE, T., GOTTARDO, R., HAHNE, F., HANSEN, K. D., IRIZARRY, R. A., LAWRENCE, M., LOVE, M. I., MACDONALD, J., OBENCHAIN, V., OLES, A. K., PAGES, H., REYES, A., SHANNON, P., SMYTH, G. K., TENENBAUM, D., WALDRON, L. \& MORGAN, M. 2015. Orchestrating high-throughput genomic analysis with Bioconductor. Nat Methods, 12, 11521.

JEUKEN, A., KESER, B. J., KHAN, E., BROUWER, A., KOEMAN, J. \& DENISON, M. S. 2003. Activation of the Ah receptor by extracts of dietary herbal supplements, vegetables, and fruits. J Agric Food Chem, 51, 5478-87. 
bioRxiv preprint doi: https://doi.org/10.1101/2022.02.10.479676; this version posted February 10, 2022. The copyright holder for this preprint (which was not certified by peer review) is the author/funder. All rights reserved. No reuse allowed without permission.

Brinkmann et. al

1061

1062

1063

1064

1065

1066

1067

1068

1069

1070

1071

1072

1073

1074

1075

1076

1077

1078

1079

1080

1081

1082

1083

1084

1085

1086

1087

1088

1089

1090

1091

1092

1093

1094

1095

1096

1097

1098

1099

1100

1101

1102

1103

1104

1105

1106

1107

1108

1109

1110

1111

1112

JONES, L. M., RAYSON, S. J., FLEMMING, A. J. \& URWIN, P. E. 2013. Adaptive and specialised transcriptional responses to xenobiotic stress in Caenorhabditis elegans are regulated by nuclear hormone receptors. PLoS One, 8, e69956.

KAHN, N. W., REA, S. L., MOYLE, S., KELL, A. \& JOHNSON, T. E. 2008. Proteasomal dysfunction activates the transcription factor SKN-1 and produces a selective oxidative-stress response in Caenorhabditis elegans. Biochem J, 409, 205-13.

KAMATH, R. S. \& AHRINGER, J. 2003. Genome-wide RNAi screening in Caenorhabditis elegans. Methods, 30, 313-21.

KAUFFMANN, A., GENTLEMAN, R. \& HUBER, W. 2009. arrayQualityMetrics--a bioconductor package for quality assessment of microarray data. Bioinformatics, 25, 415-6.

KOHLE, C. \& BOCK, K. W. 2007. Coordinate regulation of Phase I and II xenobiotic metabolisms by the Ah receptor and Nrf2. Biochem Pharmacol, 73, 1853-62.

KUBLI, S. P., BASSI, C., ROUX, C., WAKEHAM, A., GOBL, C., ZHOU, W., JAFARI, S. M., SNOW, B., JONES, L., PALOMERO, L., THU, K. L., CASSETTA, L., SOONG, D., BERGER, T., RAMACHANDRAN, P., BANIASADI, S. P., DUNCAN, G., LINDZEN, M., YARDEN, Y., HERRANZ, C., LAZARO, C., CHU, M. F., HAIGHT, J., TINTO, P., SILVESTER, J., CESCON, D. W., PETIT, A., PETTERSSON, S., POLLARD, J. W., MAK, T. W., PUJANA, M. A., CAPPELLO, P. \& GORRINI, C. 2019. AhR controls redox homeostasis and shapes the tumor microenvironment in BRCA1-associated breast cancer. Proc Natl Acad Sci U S A, 116, 3604-3613.

LAHTEENVUO, J. \& ROSENZWEIG, A. 2012. Effects of aging on angiogenesis. Circ Res, 110, 1252-64.

LASKOWSKI, R., MACARTHUR, M., MOSS, D. \& THORNTON, J. 1993. PROCHECK: a program to check the stereochemical quality of protein structures. J Appl Crystallogr 283-291.

LEMIRE, B. D., BEHRENDT, M., DECORBY, A. \& GASKOVA, D. 2009. C. elegans longevity pathways converge to decrease mitochondrial membrane potential. Mech Ageing Dev, 130, 461-5.

LI, W., SUN, K., HU, F., CHEN, L., ZHANG, X., WANG, F. \& YAN, B. 2021. Protective effects of natural compounds against oxidative stress in ischemic diseases and cancers via activating the Nrf2 signaling pathway: A mini review. J Biochem Mol Toxicol, 35, e22658.

LIAO, V. H., YU, C. W., CHU, Y. J., LI, W. H., HSIEH, Y. C. \& WANG, T. T. 2011. Curcumin-mediated lifespan extension in Caenorhabditis elegans. Mech Ageing Dev, 132, 480-7.

LIM, G. P., CHU, T., YANG, F., BEECH, W., FRAUTSCHY, S. A. \& COLE, G. M. 2001. The curry spice curcumin reduces oxidative damage and amyloid pathology in an Alzheimer transgenic mouse. J Neurosci, 21, 8370-7.

LIU, Y., SAMUEL, B. S., BREEN, P. C. \& RUVKUN, G. 2014. Caenorhabditis elegans pathways that surveil and defend mitochondria. Nature, 508, 406-10.

LIVAK, K. J. \& SCHMITTGEN, T. D. 2001. Analysis of relative gene expression data using real-time quantitative PCR and the 2(-Delta Delta $C(T)$ ) Method. Methods, 25, 402-8.

MAGLIONI, S., ARSALAN, N., HAMACHER, A., AFSHAR, S., SCHIAVI, A., BELLER, M. \& VENTURA, N. 2022. High-Content $C$. elegans Screen Identifies Natural Compounds Impacting MitochondriaLipid Homeostasis and Promoting Healthspan. Cells, 11, 100.

MANDAL, P. K. 2005. Dioxin: a review of its environmental effects and its aryl hydrocarbon receptor biology. J Comp Physiol B, 175, 221-30.

MAO, K., JI, F., BREEN, P., SEWELL, A., HAN, M., SADREYEV, R. \& RUVKUN, G. 2019. Mitochondrial Dysfunction in C. elegans Activates Mitochondrial Relocalization and Nuclear Hormone Receptor-Dependent Detoxification Genes. Cell Metab, 29, 1182-1191 e4.

MARINKOVIC, N., PASALIC, D., FERENCAK, G., GRSKOVIC, B. \& STAVLENIC RUKAVINA, A. 2010. Dioxins and human toxicity. Arh Hig Rada Toksikol, 61, 445-53.

MARTI-RENOM, M. A., STUART, A. C., FISER, A., SANCHEZ, R., MELO, F. \& SALI, A. 2000. Comparative protein structure modeling of genes and genomes. Annu Rev Biophys Biomol Struct, 29, 291325.

MINAMI, K., NAKAJIMA, M., FUJIKI, Y., KATOH, M., GONZALEZ, F. J. \& YOKOI, T. 2008. Regulation of insulin-like growth factor binding protein-1 and lipoprotein lipase by the aryl hydrocarbon receptor. J Toxicol Sci, 33, 405-13. 
bioRxiv preprint doi: https://doi.org/10.1101/2022.02.10.479676; this version posted February 10, 2022. The copyright holder for this preprint (which was not certified by peer review) is the author/funder. All rights reserved. No reuse allowed without permission.

Brinkmann et. al

MOHAMMADI-BARDBORI, A., AKBARIZADEH, A. R., DELU, F. \& RANNUG, A. 2016. Chromatin remodeling by curcumin alters endogenous aryl hydrocarbon receptor signaling. Chem Biol Interact, 252, 19-27.

MOREL, Y. \& BAROUKI, R. 1998. Down-regulation of cytochrome P450 1A1 gene promoter by oxidative stress. Critical contribution of nuclear factor 1. J Biol Chem, 273, 26969-76.

MORLEY, J. F., BRIGNULL, H. R., WEYERS, J. J. \& MORIMOTO, R. I. 2002. The threshold for polyglutamine-expansion protein aggregation and cellular toxicity is dynamic and influenced by aging in Caenorhabditis elegans. Proc Natl Acad Sci U S A, 99, 10417-22.

MOTTO, I., BORDOGNA, A., SOSHILOV, A. A., DENISON, M. S. \& BONATI, L. 2011. New aryl hydrocarbon receptor homology model targeted to improve docking reliability. J Chem Inf Model, 51, 2868-81.

NISHIUMI, S., YOSHIDA, K. \& ASHIDA, H. 2007. Curcumin suppresses the transformation of an aryl hydrocarbon receptor through its phosphorylation. Arch Biochem Biophys, 466, 267-73.

OKEY, A. B., DUBE, A. W. \& VELLA, L. M. 1984. Binding of benzo(a)pyrene and dibenz(a,h)anthracene to the Ah receptor in mouse and rat hepatic cytosols. Cancer Res, 44, 1426-32.

OLIVER, J. M., STONER, L., ROWLANDS, D. S., CALDWELL, A. R., SANDERS, E., KREUTZER, A., MITCHELL, J. B., PURPURA, M. \& JAGER, R. 2016. Novel Form of Curcumin Improves Endothelial Function in Young, Healthy Individuals: A Double-Blind Placebo Controlled Study. J Nutr Metab, 2016, 1089653.

PECKER, M. S., IM, W. B., SONN, J. K. \& LEE, C. O. 1986. Effect of norepinephrine and cyclic AMP on intracellular sodium ion activity and contractile force in canine cardiac Purkinje fibers. Circ Res, 59, 390-7.

PFAFFL, M. W. 2001. A new mathematical model for relative quantification in real-time RT-PCR. Nucleic Acids Res, 29, e45.

POLAND, A. \& GLOVER, E. 1975. Genetic Expression of Aryl Hydrocarbon Hydroxylase by 2,3,7,8Tetrachlorodibenzo-<em>p</em>-dioxin: Evidence for a Receptor Mutation in Genetically Non-responsive Mice. Molecular Pharmacology, 11, 389-398.

POLAND, A., GLOVER, E. \& KENDE, A. S. 1976. Stereospecific, high affinity binding of 2,3,7,8tetrachlorodibenzo-p-dioxin by hepatic cytosol. Evidence that the binding species is receptor for induction of aryl hydrocarbon hydroxylase. J Biol Chem, 251, 4936-46.

POWELL-COFFMAN, J. A., BRADFIELD, C. A. \& WOOD, W. B. 1998. Caenorhabditis elegans orthologs of the aryl hydrocarbon receptor and its heterodimerization partner the aryl hydrocarbon receptor nuclear translocator. Proc Natl Acad Sci U S A, 95, 2844-9.

PREIBISCH, S., SAALFELD, S. \& TOMANCAK, P. 2009. Globally optimal stitching of tiled 3D microscopic image acquisitions. Bioinformatics, 25, 1463-5.

QIN, H. \& POWELL-COFFMAN, J. A. 2004. The Caenorhabditis elegans aryl hydrocarbon receptor, AHR-1, regulates neuronal development. Dev Biol, 270, 64-75.

QIN, H., ZHAI, Z. \& POWELL-COFFMAN, J. A. 2006. The Caenorhabditis elegans AHR-1 transcription complex controls expression of soluble guanylate cyclase genes in the URX neurons and regulates aggregation behavior. Dev Biol, 298, 606-15.

REGITZ, C., FITZENBERGER, E., MAHN, F. L., DUSSLING, L. M. \& WENZEL, U. 2016. Resveratrol reduces amyloid-beta (Abeta(1)(-)(4)(2))-induced paralysis through targeting proteostasis in an Alzheimer model of Caenorhabditis elegans. Eur J Nutr, 55, 741-747.

RINALDI, A. L., MORSE, M. A., FIELDS, H. W., ROTHAS, D. A., PEI, P., RODRIGO, K. A., RENNER, R. J. \& MALLERY, S. R. 2002. Curcumin activates the aryl hydrocarbon receptor yet significantly inhibits (-)-benzo(a)pyrene-7R-trans-7,8-dihydrodiol bioactivation in oral squamous cell carcinoma cells and oral mucosa. Cancer Res, 62, 5451-6.

RISTOW, M. \& SCHMEISSER, K. 2014. Mitohormesis: Promoting Health and Lifespan by Increased Levels of Reactive Oxygen Species (ROS). Dose Response, 12, 288-341.

RITCHIE, M. E., PHIPSON, B., WU, D., HU, Y., LAW, C. W., SHI, W. \& SMYTH, G. K. 2015. limma powers differential expression analyses for RNA-sequencing and microarray studies. Nucleic Acids Res, 43, e47. 
bioRxiv preprint doi: https://doi.org/10.1101/2022.02.10.479676; this version posted February 10, 2022. The copyright holder for this preprint (which was not certified by peer review) is the author/funder. All rights reserved. No reuse allowed without permission.

Brinkmann et. al

1165

1166

1167

1168

1169

1170

1171

1172

1173

1174

1175

1176

1177

1178

1179

1180

1181

1182

1183

1184

1185

1186

1187

1188

1189

1190

1191

1192

1193

1194

1195

1196

1197

1198

1199

1200

1201

1202

1203

1204

1205

1206

1207

1208

1209

1210

1211

1212

1213

1214

1215

1216

1217

SAKAKIBARA, H., NAKAGAWA, S., WAKAMEDA, H., NAKAGIRI, Y., KAMATA, K., DAS, S. K., TSUJI, T. \& KANAZAWA, K. 2005. Effects of Japanese kelp (kombu) on life span of benzo[a]pyrene-fed mice. J Nutr Sci Vitaminol (Tokyo), 51, 369-73.

SALI, A. \& BLUNDELL, T. L. 1993. Comparative protein modelling by satisfaction of spatial restraints. J Mol Biol, 234, 779-815.

SANDOVAL-ACUNA, C., FERREIRA, J. \& SPEISKY, H. 2014. Polyphenols and mitochondria: an update on their increasingly emerging ROS-scavenging independent actions. Arch Biochem Biophys, 559, 75-90.

SCHINDELIN, J., ARGANDA-CARRERAS, I., FRISE, E., KAYNIG, V., LONGAIR, M., PIETZSCH, T., PREIBISCH, S., RUEDEN, C., SAALFELD, S., SCHMID, B., TINEVEZ, J. Y., WHITE, D. J., HARTENSTEIN, V., ELICEIRI, K., TOMANCAK, P. \& CARDONA, A. 2012. Fiji: an open-source platform for biologicalimage analysis. Nat Methods, 9, 676-82.

SCHMIDT, J. V., SU, G. H., REDDY, J. K., SIMON, M. C. \& BRADFIELD, C. A. 1996. Characterization of a murine Ahr null allele: involvement of the Ah receptor in hepatic growth and development. Proc Natl Acad Sci U S A, 93, 6731-6.

SCHRÖDINGER, L. 2010. The PyMOL Molecular Graphics System. Version 1.3r1 ed.

SHAHAM, S. 2006. WormBook: Methods in cell biology. WormBook.

SHANNON, P., MARKIEL, A., OZIER, O., BALIGA, N. S., WANG, J. T., RAMAGE, D., AMIN, N., SCHWIKOWSKI, B. \& IDEKER, T. 2003. Cytoscape: a software environment for integrated models of biomolecular interaction networks. Genome Res, 13, 2498-504.

SHEN, M. Y. \& SALI, A. 2006. Statistical potential for assessment and prediction of protein structures. Protein Sci, 15, 2507-24.

SHI, H., LIU, J. \& GAO, H. 2021. Benzo(alpha)pyrene induces oxidative stress and inflammation in human vascular endothelial cells through AhR and NF-kappaB pathways. Microvasc Res, 137, 104179.

SMIRNOVA, A., WINCENT, E., VIKSTROM BERGANDER, L., ALSBERG, T., BERGMAN, J., RANNUG, A. \& RANNUG, U. 2016. Evidence for New Light-Independent Pathways for Generation of the Endogenous Aryl Hydrocarbon Receptor Agonist FICZ. Chem Res Toxicol, 29, 75-86.

SMITH, C. J., O'BRIEN, T., CHATZIGEORGIOU, M., SPENCER, W. C., FEINGOLD-LINK, E., HUSSON, S. J., HORI, S., MITANI, S., GOTTSCHALK, A., SCHAFER, W. R. \& MILLER, D. M., 3RD 2013. Sensory Neuron Fates Are Distinguished by a Transcriptional Switch that Regulates Dendrite Branch Stabilization. Neuron, 79, 266-80.

SOMMER, C., STRÄHLE, C., KÖTHE, U. \& HAMPRECHT, F. A. 2011. lastik: Interactive Learning and Segmentation Toolkit. Eighth IEEE International Symposium on Biomedical Imaging (ISBI). Proceedings.

SPYRIDOPOULOS, I., FICHTLSCHERER, S., POPP, R., TOENNES, S. W., FISSLTHALER, B., TREPELS, T., ZERNECKE, A., LIEHN, E. A., WEBER, C., ZEIHER, A. M., DIMMELER, S. \& HAENDELER, J. 2008. Caffeine enhances endothelial repair by an AMPK-dependent mechanism. Arterioscler Thromb Vasc Biol, 28, 1967-74.

TIMMONS, L. \& FIRE, A. 1998. Specific interference by ingested dsRNA. Nature, 395, 854.

VAN HAM, T. J., THIJSSEN, K. L., BREITLING, R., HOFSTRA, R. M., PLASTERK, R. H. \& NOLLEN, E. A. 2008. C. elegans model identifies genetic modifiers of alpha-synuclein inclusion formation during aging. PLoS Genet, 4, e1000027.

VONDRACEK, J., UMANNOVA, L. \& MACHALA, M. 2011. Interactions of the aryl hydrocarbon receptor with inflammatory mediators: beyond CYP1A regulation. Curr Drug Metab, 12, 89-103.

WANG, X., LI, S., LIU, L., JIAN, Z., CUI, T., YANG, Y., GUO, S., YI, X., WANG, G., LI, C., GAO, T. \& LI, K. 2019. Role of the aryl hydrocarbon receptor signaling pathway in promoting mitochondrial biogenesis against oxidative damage in human melanocytes. J Dermatol Sci, 96, 33-41.

WILLIAMS, E. G., MOUCHIROUD, L., FROCHAUX, M., PANDEY, A., ANDREUX, P. A., DEPLANCKE, B. \& AUWERX, J. 2014. An evolutionarily conserved role for the aryl hydrocarbon receptor in the regulation of movement. PLoS Genet, 10, e1004673.

WOOD, J. G., ROGINA, B., LAVU, S., HOWITZ, K., HELFAND, S. L., TATAR, M. \& SINCLAIR, D. 2004. Sirtuin activators mimic caloric restriction and delay ageing in metazoans. Nature, 430, 686-9. 
Brinkmann et. al

WU, H., HUANG, C., TAKI, F. A., ZHANG, Y., DOBBINS, D. L., LI, L., YAN, H. \& PAN, X. 2015. Benzoalpha-pyrene induced oxidative stress in Caenorhabditis elegans and the potential involvements of microRNA. Chemosphere, 139, 496-503.

XUE, Z., LI, D., YU, W., ZHANG, Q., HOU, X., HE, Y. \& KOU, X. 2017. Mechanisms and therapeutic prospects of polyphenols as modulators of the aryl hydrocarbon receptor. Food Funct, 8 , 1414-1437.

YANG, J. S., NAM, H. J., SEO, M., HAN, S. K., CHOI, Y., NAM, H. G., LEE, S. J. \& KIM, S. 2011. OASIS: online application for the survival analysis of lifespan assays performed in aging research. PLoS One, 6, e23525.

YI, T., WANG, J., ZHU, K., TANG, Y., HUANG, S., SHUI, X., DING, Y., CHEN, C. \& LEI, W. 2018. Aryl Hydrocarbon Receptor: A New Player of Pathogenesis and Therapy in Cardiovascular Diseases. Biomed Res Int, 2018, 6058784.

ZHANG, L., MA, J., TAKEUCHI, M., USUI, Y., HATTORI, T., OKUNUKI, Y., YAMAKAWA, N., KEZUKA, T., KURODA, M. \& GOTO, H. 2010. Suppression of experimental autoimmune uveoretinitis by inducing differentiation of regulatory $T$ cells via activation of aryl hydrocarbon receptor. Invest Ophthalmol Vis Sci, 51, 2109-17.

ZHANG, S., QIN, C. \& SAFE, S. H. 2003. Flavonoids as aryl hydrocarbon receptor agonists/antagonists: effects of structure and cell context. Environ Health Perspect, 111, 1877-82. 